\title{
Vestidas en la historia: \\ una mirada a la colección de indumentaria femenina del Museo Histórico Nacional (Buenos Aires, Argentina)
}

\author{
[Dressed in History: a Look at the Collection of Women's Clothing \\ at the National Historical Museum (Buenos Aires, Argentina)]
}

\author{
Juliana Ullua \\ (Museo Histórico Nacional, \\ Argentina) \\ julianaullua@hotmail.com
}

\author{
Inés Van Peteghem \\ (Museo Histórico Nacional / \\ Universidad de Buenos Aires / IIEGE, \\ Argentina*) \\ inevanp@gmail.com
}

\section{Resumen}

Distintas mujeres de la primera mitad del siglo XIX, en su mayoría pertenecientes a la elite porteña, vistieron sobre sus cuerpos diversas prendas, como vestidos, capas, batas, mantillas, que décadas más tarde fueron donadas a uno de los principales museos históricos de Argentina, el Museo Histórico Nacional. En este artículo pretendemos estudiar esas prendas como objetos que reflejan no solo las vidas cotidianas de la época, en las que fueron usadas, sino también cómo esos objetos se convirtieron en piezas dignas de ser testimonio de la historia nacional.

Otro de nuestros objetivos con este artículo es generar nuevos conocimientos sobre las mujeres del pasado, que logren enriquecer los guiones museológicos actuales. Además, buscamos sumar un tipo de fuente material al estudio de la indumentaria que permita hacer un aporte distinto sobre la circulación de estas prendas, como así también indagar sobre dimensiones simbólicas y políticas que se desprenden de su uso.

Palabras claves: Museo Histórico Nacional; Mujeres; Indumentaria; Cultura Material Femenina; Buenos Aires.

\begin{abstract}
Different women of the first half of the 19th century, mostly belonging to the Buenos Aires elite, wore various garments on their bodies, such as dresses, capes, robes, mantillas, which decades later were donated to one of the main historical museums of Argentina, the National Historical Museum. In this article we intend to study these garments as objects that reflect not only the daily lives of the time in which they were used, but also how those objects became pieces worthy of being a testimony for national history.

Another of our objectives with this article is to generate new knowledge about the women of the past, which enriches the current museological scripts. In addition, we seek to add a type of material source to the study of clothing that allows a different contribution on the circulation of these garments, as well as to inquire about symbolic and political dimensions that emerge from their use.
\end{abstract}

Keywords: National Historical Museum; Women; Costume; Female Material Culture; Buenos Aires.

Recibido: $26 / 02 / 2020$

Evaluación: 17/06/2020

Aceptado: 24/08/2020

Anuario de la Escuela de Historia Virtual - Año 11 - N 18 - 2020: pp. 69-106.

ISSN: 1853-7049

http://revistas.unc.edu.ar/index.php/anuariohistoria

\footnotetext{
* Miembro del proyecto Filocyt FC19-023 "De costuras, bordados, modas y costureritxs. Abordajes interdisciplinarios en torno al trabajo de la aguja, el consumo de indumentaria y las artes textiles. Buenos Aires, siglos XIX, XX y XXI" - Instituto de Investigaciones de Estudios de Género, FFyL, UBA.
} 


\section{Vestidas en la historia: una mirada a la colección de indumentaria femenina del Museo Histórico Nacional (Buenos Aires, Argentina)}

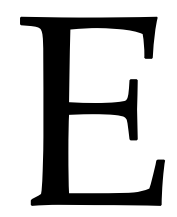

1 presente artículo tiene como fin acercar la investigación resultante del trabajo realizado en el proyecto de puesta en valor de la colección de indumentaria femenina del Museo Histórico Nacional (de aquí en adelante: MHN), ejecutado por las encargadas del taller de Conservación Textil del mismo museo. Se presenta aquí la sistematización que hemos logrado alcanzar sobre el trabajo realizado a lo largo de varios años.

Es parte de nuestra investigación analizar las formas de representación de las mujeres en el museo y su historia, para así desentrañar las relaciones de poder en torno al género intrínsecas a nuestra sociedad hasta nuestros días. La importancia de este proyecto radica no solo en la relevancia de la colección en sí misma, sino también en la necesidad actual de abrir debates en torno a temas no abordados en el museo, como el rol de las mujeres en la historia nacional.

La tarea fundamental que deben plantearse las instituciones públicas que preservan patrimonio es cumplir con la protección y conservación, la investigación y la difusión del mismo. La demanda actual de mayor conocimiento sobre las colecciones patrimoniales es palpable, y esta debe ser una prioridad para los museos, con el objetivo de ahondar aún más en sus colecciones. Es así que nuestro trabajo pretende satisfacer, en principio, esa necesidad a partir de una profunda investigación de esta colección y una mejora de su estado de conservación y guarda.

El valor de la colección de indumentaria femenina del MHN consiste principalmente en que su historia puede dar testimonio de cuáles fueron las vicisitudes atravesadas por los objetos pertenecientes a mujeres a lo largo de toda su existencia y aún en la actualidad. Podemos extraer información tanto en su historia de uso, en su derrotero posterior en el resguardo familiar, en la subsiguiente llegada al museo y su circulación en el mismo y en las exposiciones.

Conocer la historia de esta porción de la colección del MHN puede, a su vez, contribuir a las investigaciones relativas a la creación de los museos históricos en Argentina y cómo se produjeron los procesos de construcción de sus colecciones.

Centrar el interés en la colección de indumentaria femenina hoy en día responde sin duda a una voluntad histórica de dar visibilidad a las mujeres, ${ }^{1}$ así como de exponer cuá-

\footnotetext{
${ }^{1}$ Así también, es una deuda pendiente incorporar a los guiones museológicos y a la colección misma del museo piezas referentes a la presencia de los pueblos originarios, los trabajadores, las trabajadoras y el movimiento obrero, las corrientes migratorias y el colectivo LGBTQ+.
}

Anuario de la Escuela de Historia Virtual - Año 11 - N 18 - 2020: pp. 69-106. ISSN: 1853-7049 
les fueron las relaciones de poder a las que las mismas fueron, y somos, expuestas. Significa también dar entidad a su vida, sus acciones y empresas. Corresponde a una ruptura clara dentro de la historia del MHN, lo que instaura, a su vez, debates contemporáneos en el relato establecido y decimonónico y busca ir más allá del guión centrado en la cronología y lo masculino.

Durante décadas el MHN fomentó la exhibición de gran cantidad de uniformes, armas e imágenes de militares y batallas. Por el contrario, los objetos relativos a mujeres ocuparon un lugar subsidiario en sus salas. Para Marián López Fernández Cao ponderar los objetos que aluden a la violencia contribuye a reproducir un imaginario donde el mensaje válido para transmitir a las nuevas generaciones se basa en la importancia del hombre y sus hazañas. Por otro lado, la escasa presencia de objetos de mujeres tiende a reducir sus acciones al punto de volverlas insignificantes. La autora agrega que: "Naturalizar esta jerarquía es tergiversar las prácticas sociales y culturales marcando qué prácticas humanas parecen necesarias, luego valiosas y cuáles contingentes, luego prescindibles" (López Fernández Cao, 2011, p. 79).

Hoy "el concepto de museo constituye un terreno de disputa sobre el que convergen miradas e intereses de los más diversos" (Bermejo y Cortés Aliaga, 2019, p. 56). En este terreno nos toca manejarnos, pelear si se quiere, para abrir pequeños resquicios en los que depositar interrogantes, aunque menos sea, con la esperanza de sembrar un brote a futuro. Este artículo intenta eso mismo, abrir un espacio para el debate venidero, partiendo de la valorización de una colección por mucho tiempo minimizada.

Siguiendo esta línea, Cortés Aliaga y Cuevas Pérez abordaron las omisiones y ausencias femeninas en la historiografía, un aspecto que se acentúa en los museos. Los autores sostienen que "los museos y sus colecciones se constituyen como espacios complejos que, si bien tienen el potencial de expandir los márgenes de entendimiento de distintos períodos históricos a partir de la escritura, de igual modo poseen la potestad de restringirlos" (Cortés Aliaga y Cuevas Pérez, 2018, p. 175). A su vez, plantean que este aspecto podría subsanarse comprendiendo que: "La investigación al interior de la institución fortalece y promueve la búsqueda de nuevos contextos y lenguajes" (Cortés Aliaga y Cuevas Pérez, 2018, p. 175).

En nuestra investigación de la colección de indumentaria femenina consideramos central dar lugar a las piezas textiles como fuentes, así como a la documentación existente referente a las mismas. Este estudio permite también dar relevancia al archivo histórico del museo.

A lo largo del artículo haremos una síntesis de la historia del museo y la conformación de sus colecciones, para poder situarnos espacial y temporalmente y, de ese modo, comprender las colecciones con las que hoy trabajamos. Señalaremos las características del área de conservación textil y la colección específica que allí se gestiona, para, luego, adentrarnos en particular en la colección de indumentaria femenina, su historia y sus características. 
En nuestro tratamiento de las piezas textiles como fuentes podemos recabar información sobre la materialidad de las mismas, así como extraer pistas sobre su confección y manufactura, lo que nos permite tejer lazos con la historiografía existente acerca de las formas de producción, circulación y comercialización en el Buenos Aires del siglo XIX. Las piezas, relacionadas con los estudios existentes sobre la indumentaria de la época, nos posibilitan pensar en las formas de uso de las mismas, así como en aspectos de la vida cotidiana relacionados a ellas.

La documentación vinculada a las piezas, por su parte, nos permite usualmente conocer sobre la historia misma de los objetos, así como también ciertos aspectos biográficos de sus dueñas, generalmente centrándose en la relación con los "hombres importantes" de nuestra historia. También logramos advertir cuál ha sido el derrotero de su nombre en el recorrido sucesivo de los objetos, ya que muchas veces se diluyen con el paso del tiempo. Podemos conocer el tejido de relaciones sociales que se estructura en torno a las piezas, las mujeres que las usaron y aquellas que asumieron el rol de cuidadoras de las mismas, y los caminos de circulación hasta su llegada al museo por medio de la donación o adquisición.

Al investigar desde el hoy piezas de una institución pública, consideramos que debemos ser conscientes de la existencia de "amenazas" en los discursos establecidos, tal como señala Andrés Gutiérrez Usillos (2012, p. 15). Como hemos mencionado, los megadiscursos tradicionales, cimentados sobre esquemas de acontecimientos impuestos por varones, redundan en el silenciamiento de las voces y los nombres de las mujeres, como formas de subestimación camufladas y sutiles, que se perpetúan en la historia, incluida la de los museos. Debemos entender los silencios y las ausencias resultantes en su contexto temporal, pero repensándolos desde nuestro presente.

Siempre las atribuciones de pertenencia de las piezas y sus historias se tratan de un testimonio escrito proveniente de los donantes o, incluso, de los dueños. Siguiendo este último aspecto, según Felipe Criado Boado (2012, p. 18): “Los objetos (...) no hablan por sí mismos: los objetos son mudos; dos veces mudos si proceden de la historia, pues los sujetos que podrían haber hablado de ellos están muertos y ya no hablan, aunque dispongamos de representaciones literarias de su racionalidad". Nos permitiremos aquí discernir con Criado Boado en relación a la negación que efectúa sobre las representaciones escritas de aquellos sujetos que puedan hablar por los objetos. Consideramos que estas representaciones son parte de la historia del objeto, hablan del mismo y de su periplo. Más aun considerando la naturaleza de las donaciones del MHN, las representaciones sobre los objetos se convierten en fuentes ineludibles para reconstruir la historia de los mismos. Esto no significa, por supuesto, que consideremos los testimonios allí plasmados como inequívocos y como el único análisis a realizar sobre los objetos.

Resulta interesante destacar cuáles son las representaciones que se construyen en torno a las piezas patrimoniales y su valor, podemos sostener basándonos en los relatos construidos en torno a sus donaciones, que el valor de las mismas radica principalmente en las 
redes de intercambios en las que se vieron envueltas. Mayormente, se resalta la importancia de la personalidad que las poseía, de quién las obsequió o para qué sirvieron las mismas, como el caso que veremos del abanico de Laurena Ferrari, que se utilizó como proveedor de material para la bandera de Los Andes. Como destaca Arjun Appadurai (1991, p. 19), el valor reside en esos intercambios y en las formas en que "el deseo y la demanda, el sacrificio recíproco y el poder, interactúan para crear el valor económico en situaciones sociales específicas".

\section{Historia del Museo Histórico Nacional y sus colecciones}

En mayo de 1889 el intendente de la Ciudad de Buenos Aires Francisco Seeber (1841-1913) firma un decreto que designaba una comisión a la cual se le encarga la fundación de "un museo nacional". Adscribiendo a la historiografía liberal mitrista finisecular, que sostiene el nacimiento del pueblo argentino en las jornadas revolucionarias de mayo de $1810 \mathrm{y}$ señala como gérmenes de nuestra historia las glorias de la revolución y las luchas independentistas, esta comisión tenía el propósito de mantener "las tradiciones de la Revolución de Mayo y de la guerra de la Independencia" (Carman, 2013, p. 30), una tarea de trascendental interés nacional. Respondía también al interés estatal por la cuestión nacional vigente desde 1880 y que se plasmó en diversas políticas públicas tendientes a inculcar una nacionalidad argentina en el conjunto de la sociedad. Esta comisión no cumplió finalmente su cometido, pero marcó las directrices de los fundamentos de creación del museo.

El Museo Histórico de la Capital fue fundado oficialmente el 30 de agosto de 1890, por otro decreto del intendente Seeber, quien nombró a Adolfo Pedro Carranza como su director. Carranza pertenecía a una familia de la elite porteña, hijo de Adolfo E. Carranza, empresario y comerciante ultramarino hacia el interior del país, propietario de tierras en Santa Fe, Santiago del Estero y Buenos Aires, y cercano a la clase dirigente. Por parte de su madre, María Eugenia del Mármol y Demaria, A. P. Carranza se encontraba vinculado a los Escalada. Que su madre era sobrina de Remedios de Escalada de San Martín, sería un dato que Carranza "no se cansaría de repetir y exaltar a lo largo de su gestión al frente del Museo Histórico Nacional" (Carman, 2013, p. 38). Podemos suponer y demostrar que la tarea de Carranza al frente del MHN se condijo con el clima imperante en la elite política y su sostén historiográfico finisecular, con una ubicación como "'propagandista de la historia nacional' como lo llamaban algunos de sus contemporáneos" (Carman, 2013, p. 43).

El 26 de septiembre de 1891 el Museo pasó por medio de un decreto del Poder Ejecutivo Nacional a la órbita de la Nación, con dependencia del Ministerio del Interior. Luego de ocupar diversas sedes, se lo instaló en Parque Lezama en 1897, en una casona que pertenecía a la jurisdicción de la Municipalidad y, a instancias de Carranza, hacia abril de 1897, se efectuó la permuta por la que pasó a la égida nacional. En el mes de julio de ese año se realizó la mudanza del museo en el que se instaló también Carranza, quien establecería allí su vivienda personal.

Para Adolfo P. Carranza, desde el momento en que fue nombrado como director: 
(...) una de sus principales ocupaciones fue la implementación de una serie de estrategias destinadas a acopiar en el nuevo establecimiento cuantos objetos de valor histórico lograra reunir. Lo hizo mediante dos grandes operaciones. Por una parte, apeló a diversas personalidades pertenecientes al ámbito de la elite patricia y a coleccionistas para que donaran o prestaran al Museo objetos vinculados con el pasado nacional. Por otra parte, solicitó al intendente repetidamente la realización de las gestiones necesarias para que fueran enviados al nuevo establecimiento artefactos y obras de arte que se encontraban dispersos en diversas entidades públicas, tanto municipales como nacionales (Carman, 2013, pp. 60-61).

Sin embargo, la ayuda estatal se mostró escasa, lo que resaltó aún más el carácter personalista de la misión del Director. Predominarán como fuente de ingreso de objetos al MHN las donaciones provenientes de diversas personalidades de la elite, principalmente miembros de familias de figuras políticas: “De esta manera se daba inicio a un intento de concentración de objetos desde diferentes ámbitos estatales y privados hacia el Museo que habría de continuar durante toda la gestión de Carranza" (Carman, 2013, p. 61). En su mayoría, las donaciones privadas provenían de familiares de hombres públicos del pasado, se trataban de recuerdos de familia y respondieron en general a una voluntad de trascendencia pública y "deber patriótico".

\section{El Área de Conservación Textil y sus colecciones}

La colección de textiles del MHN se compone de banderas, estandartes, indumentaria militar, civil, religiosa, accesorios y la reciente incorporación de textiles arqueológicos, que suman un total aproximado de 2000 piezas. Podemos agrupar la colección en los siguientes grandes conjuntos, siguiendo la descripción realizada por Silvana Di Lorenzo, María Pía Villaronga y Ana Wortley a raíz del Plan Integral de Conservación y Puesta en valor del patrimonio textil histórico que las autoras desarrollaron en el museo a partir del año 2006:

-Indumentaria militar: consta de aproximadamente 50 uniformes y 600 accesorios (quepis, sombreros elásticos, cinturón con tiros, charreteras, fajas, cordones, condecoraciones y calzado).

-Indumentaria civil masculina: consta, entre otras piezas, de 25 chalecos del siglo XIX. Otra colección destacada es la de ponchos, que cuenta con 26 piezas, confeccionados con fibras de camélidos, algodón, lana o seda. 
-Pañuelos: esta colección se compone de 85 ejemplares, la mayoría conmemorativos del Primer Centenario de la Revolución de Mayo de 1810 y el resto de uso personal.

-Bandas presidenciales: la colección cuenta con 16 bandas, desde la de Justo José de Urquiza a la de Agustín P. Justo.

-Textiles etnográficos: pequeña colección integrada por fajas de lana, testeras de plumas para caballo y vinchas de lana con cuentas de vidrio.

-Banderas, guiones y estandartes: existen aproximadamente 200 (Di Lorenzo, Villaronga y Wortley, 2007, p. 25 y 26).

-Textiles arqueológicos: a mediados del año 2018 se realizó la trasferencia de la colección arqueológica privada del artista Nicolás García Uriburu al MHN. En su mayoría las piezas provienen de culturas andinas. La colección cuenta con aproximadamente 120 textiles arqueológicos y se encuentra en proceso de investigación detallada.

Finalmente, debemos mencionar la colección que nos convoca para el artículo aquí presentado, la colección de indumentaria femenina. Dentro de la colección textil del MHN, la indumentaria femenina representa una porción minoritaria, alrededor de un 3\% de las piezas. Consta de 72 piezas, las cuales fueron clasificadas en cuatro categorías por las conservadoras textiles:

-Vestimenta (11 piezas - 3 vestidos, 1 corselete, 7 varios).

-Chales, mantones y mantillas (14 piezas).

-Accesorios (35 piezas - 9 abanicos, 13 peinetas y peinetones, 3 pañuelos, 4 bandas, 2 guantes, 2 moños, 1 cartera y 1 escarapela).

-Costura y confección (12 piezas - 10 de confección y 2 varios).

La invisibilización de las mujeres está presente desde el mismo momento de conformación de la colección del museo dado que solo el 2,02\% de la colección general corresponde a objetos relacionados a mujeres. Las piezas con las que sí cuenta el museo son de gran valor, por su materialidad, significancia histórica, pertenencia y por ser representantes de una época y un estilo. Encontramos referencias a la colección de indumentaria femenina como tal en el artículo de las autoras antes mencionadas (Di Lorenzo, Villaronga y Wortley, 2007, p.25), pero no existía hasta este momento un estudio que de cuenta de una investigación completa de esta colección. Se ha destacado su importancia en distintos momentos de los últimos años, pero no se había logrado concretar un proyecto puntual que la estudie y valorice hasta este momento.. 
76 | Vestidas en la historia: una mirada a la colección de indumentaria femenina...

\section{Descripción de la colección}

\section{Vestimenta}

Dentro de esta categoría se encuentran tres vestidos que pertenecieron a Bernardina Chavarría, ${ }^{2}$ uno de ellos de estilo imperio y dos que responden al estilo romántico. Estas prendas se mencionan en una carta de donación, existente en el archivo histórico del museo, escrita por Eduardo Dudignac Mansilla el 10 de marzo de 1924 y dirigida a José Pérez Valiente de Moctezuma, quien asumió el rol de ser intermediario en la donación:

Cumpliendo con lo prometido, me es grato remitirle los vestidos siguientes: uno de moiré amarillo, otro de moiré gris oscuro, otro de casamiento de tul de seda blanco, otro de seda roce con dibujos en el tejido. Cada traje lleva la correspondiente pañoleta, todos pertenecieron a mi ilustre bisabuela Doña Bernardina Chavarría de Viamonte, dama patricia de la Independencia y socia fundadora de la Sociedad de Beneficencia de Buenos Aires y sería de mi agrado que figuraran para ser conservado en el Museo Histórico Nacional, constando ser yo el donante. ${ }^{3}$

La entrega de las piezas se hizo efectiva tres meses después, el día 27 de junio de 1924, como señala José Pérez Valiente de Moctezuma en su carta al Dr. Antonio Dellepiane, entonces Director del Museo:

Tengo el agrado de dirigirle estas líneas con el fin de poner a su disposición y hacer entrega, de acuerdo con lo que tuve el gusto de manifestarle personalmente, de un vestido antiguo de malla de seda con flores de raso aplicadas, época 1810, que desearía ceder al Museo Histórico Nacional, para que sea mostrado y conservado entre los objetos femeninos del patriciado, como perteneciente a una señora de la familia del general D. Juan José Viamonte. ${ }^{4}$

Notamos que el nombre de Bernardina Chavarría, así como otros datos de las prendas, fueron obviados al momento de ingresar a las colecciones del MHN, lo que ocasionó que hasta el comienzo de esta investigación en el museo estos objetos hayan sido catalogados como pertenecientes a "una mujer de la familia Viamonte". Pudimos esclarecer este dato al hallar la carta primigenia de Eduardo Dudignac Mansilla.

\footnotetext{
${ }^{2}$ Nacida en Buenos Aires en 1785. Al cumplir 15 años, se casó con el militar y político Juan José Viamonte con quien tuvo 10 hijos. Fue partidaria de la Independencia y donó 50 pesos fuertes para la causa. Fue una de las fundadoras de la Sociedad de Beneficencia. Murió en Buenos Aires el 18 de marzo de 1832.

${ }^{3}$ Carta de Eduardo Dudignac Mansilla dirigida a José Pérez Valiente de Moctezuma, Buenos Aires, 10 de marzo de 1924. AH MHN, FG, Caja 3, Documentos de donación, Libro XXI, Carpeta 1924, número de orden $8 / 2$.

${ }^{4}$ Carta de donación de José Pérez Valiente de Moctezuma al Dr. Antonio Dellepiane, Buenos Aires, 27 de junio de 1924. AH MHN, FG, Caja 3, Documentos de donación, Libro XXI, Carpeta 1924, número de orden 8.
} 
Otros aspectos que pudimos incorporar recientemente son los referidos a la materialidad y técnicas empleadas, dado que muchas veces los donantes desconocían estos datos, o bien, en los primeros registros del museo, podía haberse consignado información errónea. A partir de la inspección ocular y los análisis de microscopía USB realizados a las prendas pudimos detectar que el vestido imperio que el donante menciona como "de casamiento de tul de seda", en verdad se trata de tul de algodón con aplicaciones de cintas, flores y hojas de seda con acabado en gofrado. En relación a la referencia de uso, podemos agregar que hasta 1840 no existía una clara diferenciación entre los vestidos de boda y aquellos empleados para otras ceremonias o festividades.

Figura 1. Camponeschi, Ángel María,

\section{Retrato de María Eugenia Escalada de Demaría, 1808}

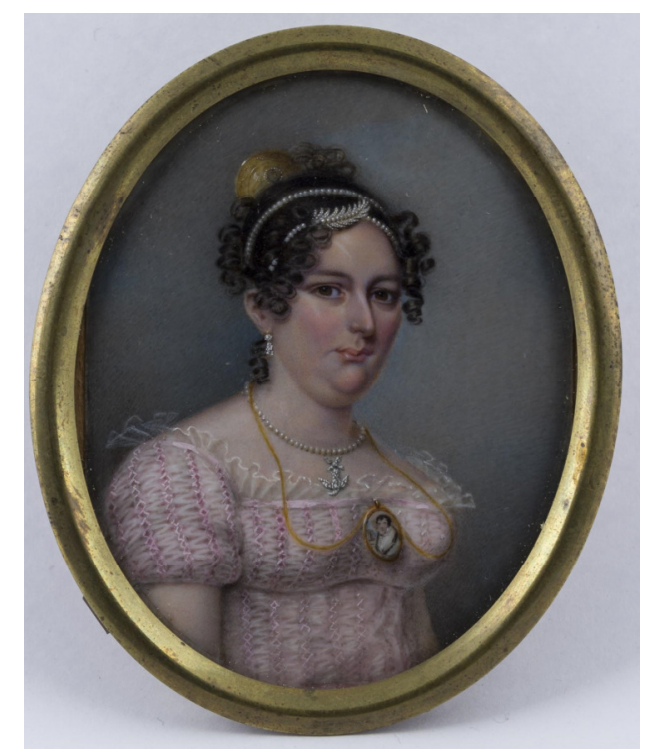

Fuente: Museo Histórico Nacional, Buenos Aires. Número de inventario: 4635. 


\section{Figura 2. Vestido imperio de Bernardina Chavarría de Viamonte}

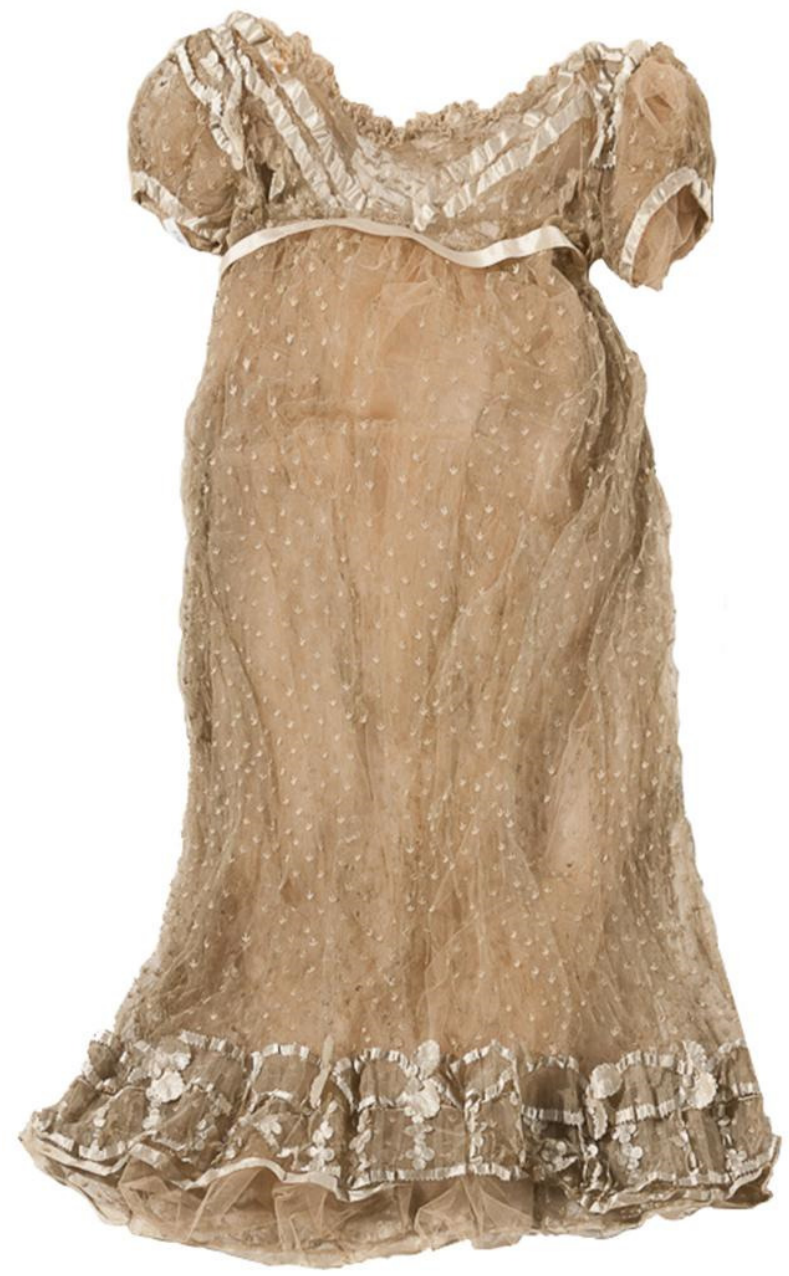

Fuente: Museo Histórico Nacional, Buenos Aires. Número de inventario: 4615.

Los otros dos vestidos son datados alrededor de 1830 y fueron confeccionados a mano en seda, con el agregado de ganchillos metálicos para los cierres de la espalda y puños. La moldería empleada es mucho más compleja, y debió requerir experiencia y astucia para su armado. Por ejemplo, en el caso de las mangas jamón, notamos que en cada vestido fueron resueltas de una manera diversa, mientras en el de seda moirè gris verdoso se emplearon hasta siete fragmentos unidos, en el otro, el abullonado es mayor y se emplearon solo tres retazos en una de sus mangas, agregando cintas a modos de lazo y botones de nácar en los puños. Ambas faldas son acampanas y tableadas y se confeccionaron uniendo hasta seis fragmentos. En las partes internas se emplearon otras telas más resistentes a 
modo de forros, como tafetanes de fibra vegetal para dar más estructura a las mangas, faldas y los ruedos.

\section{Figura 3. Vestido de Bernardina Chavarría de Viamonte}

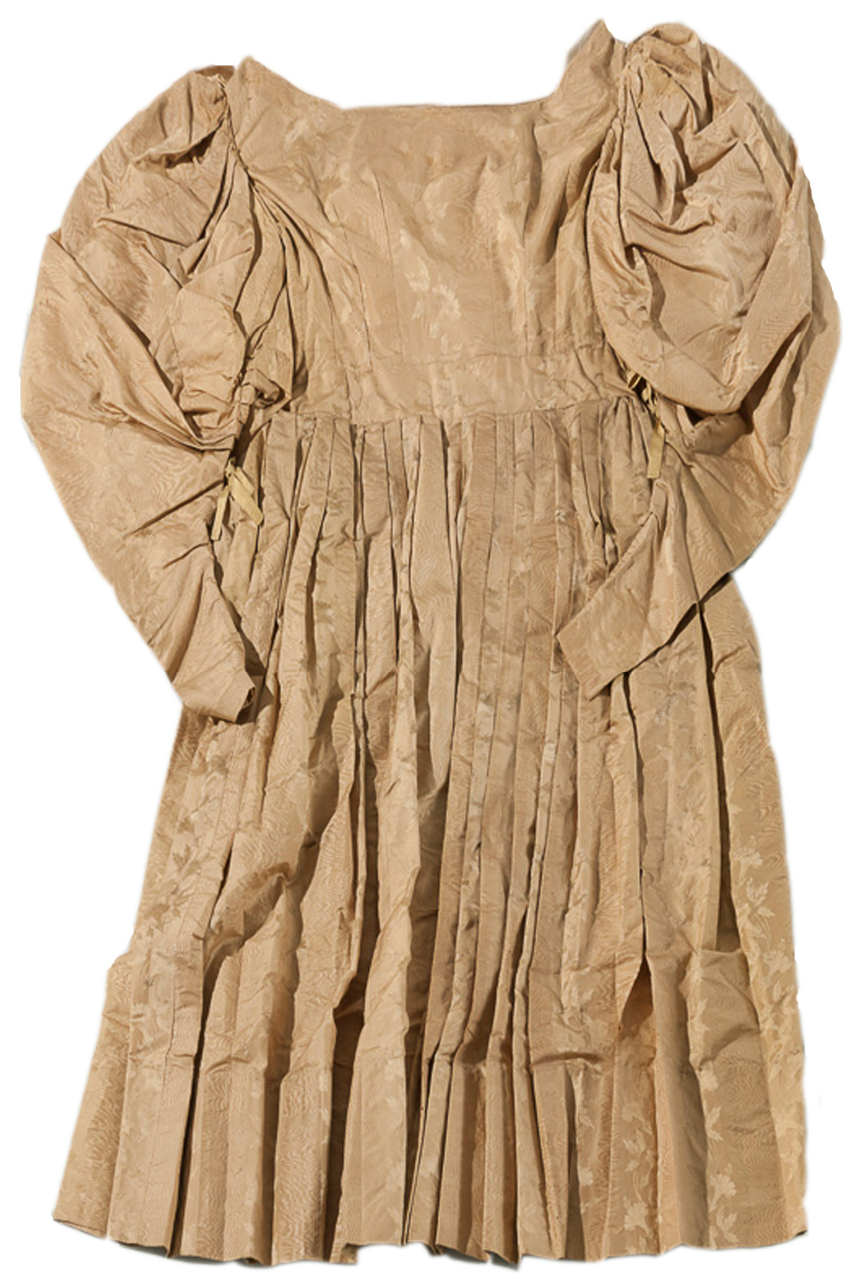

Fuente: Museo Histórico Nacional, Buenos Aires. Número de inventario: 4622. 
80 | Vestidas en la historia: una mirada a la colección de indumentaria femenina...

\section{Figura 4. Pellegrini, Carlos Enrique, Retrato de Agustina Rosas de Mansilla y su hijo Lucio}

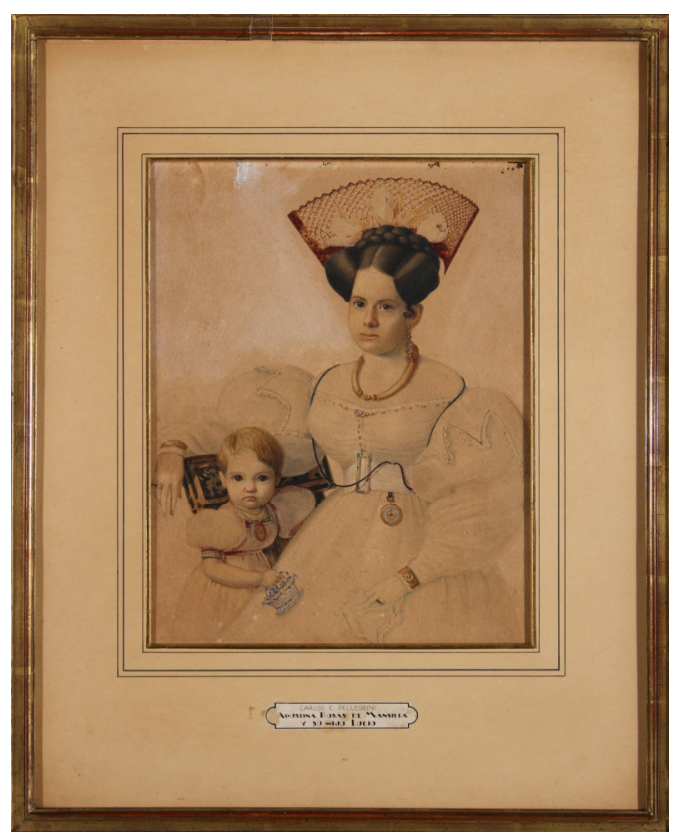

Fuente: Museo Histórico Nacional, Buenos Aires. Número de inventario: 2136.

Como se consigna en los legajos de las piezas $^{5}$ y se constata en la observación de las fotografías presentes en el archivo del museo, los vestidos mencionados fueron exhibidos en la sala Damas Patricias, en maniquíes dentro de pequeñas vitrinas, junto a los chales y abanicos. Incluso, en una fotografía de 1935, vemos el que creemos es el vestido imperio apoyado sobre el piso de una vitrina de pie.

\footnotetext{
${ }^{5}$ Legajos MHN 4614, MHN 4615 y MHN 4622. Área de Registro y Documentación de las colecciones. Museo Histórico Nacional, Buenos Aires.
}

Anuario de la Escuela de Historia Virtual - Año 11 - N 18 - 2020: pp. 69-106. ISSN: 1853-7049 
Figura 5. Sala Damas Patricias 1935

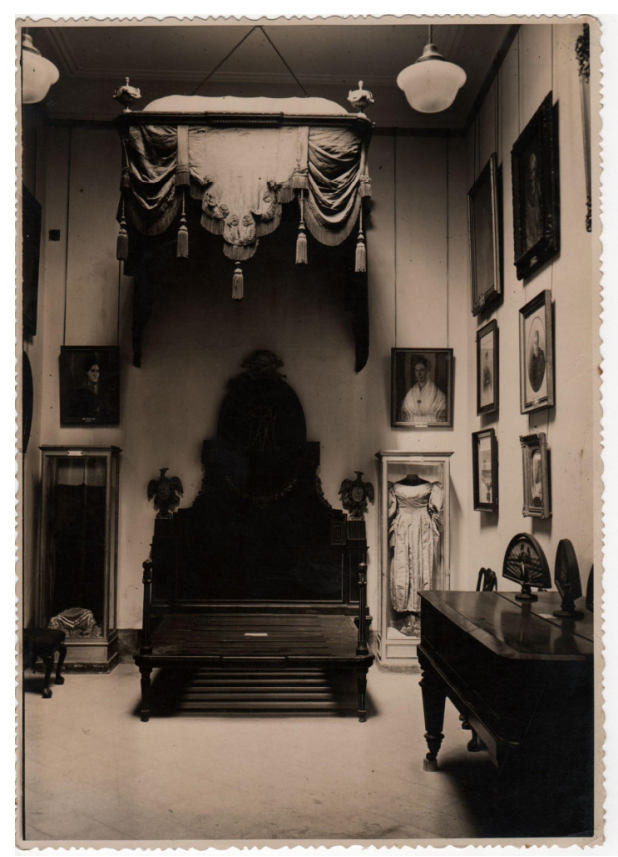

Fuente: Archivo Histórico (en adelante AH) del MHN, Fondo Institucional, Carpeta de fotografías de salas de exposición del MHN.

En la carta de donación mencionada, se señala un cuarto vestido que, en verdad se trata de tres fragmentos de seda labrada unidos con costura manual, posiblemente para la confección de una prenda que quedó a medio hacer. Resulta interesante para graficar que en el Río de la Plata podían conseguirse los más variados géneros y de gran finura, como esta tela de fabricación europea con diseños logrados por medio del empleo de tramas suplementarias, técnica que requería una tecnología de telar más compleja que la aquí disponible.

Volviendo a la confección, resulta una tarea difícil saber quiénes realizaron estas prendas. Una posibilidad es que hayan sido ejecutadas por las mismas personas que las vistieron o alguien de su entorno, ya que, como plantea Dora Barrancos, "era muy común que las mujeres de las generaciones mayores de las familias, ya fueran ricas o pobres, tuvieran a su cargo las labores de la confección y el bordado, tradición que se extendió hasta fines del siglo (...) [además] las buenas modistas se contaban con los dedos de una mano" (Barrancos, 2007, p. 74). Otra posibilidad, siguiendo a Mariana Katz, nos permite pensar en el rol cada vez más destacable del artesanado porteño, el cual -al analizar su posicionamiento frente a la Ley de Aduanas de 1835-, muestra un creciente nivel de organización. Entre este artesanado, se menciona a los sastres como un grupo ya establecido, autodenominados como "maestros", diferenciados de los dependientes, que: “En la mayoría de los 
82 | Vestidas en la historia: una mirada a la colección de indumentaria femenina...

casos, esos otros eran mujeres o, utilizando una metonimia frecuente, 'familias', que realizaban labores de inferior jerarquía" (Katz, 2017, p. 14). Sin embargo, siguiendo las investigaciones de Gabriela Mitidieri sobre trabajadores de la aguja hacia la década de 1850, la autora señala que:

Estos establecimientos [las sastrerías] concentraron la oferta de indumentaria para varones en la ciudad; las sastrerías ofrecían por lo general ropa hecha a medida, mientras que en las roperías se encontraban las prendas ya confeccionadas, de manufactura local o de importación, a precios más accesibles. Roperías y sastrerías eran espacios de consumo masculino (Mitidieri, 2017, p. 28).

En los avisos clasificados el ofrecimiento de trabajo de sastres siempre refiere a indumentaria masculina, mientras que el trabajo de costureras y modistas refiere a la indumentaria femenina (Mitidieri, 2017). Podemos mantener como posibilidad, entonces, la idea de que las mujeres confeccionaran ellas mismas sus prendas, o alguna mujer de su entorno cercano o su servicio doméstico. Sin embargo, no deja de quedar pendiente la pregunta si las costureras y modistas no eran tantas como para conformar un servicio/rubro significativo o si las mismas no han sido debidamente consignadas en las fuentes y relatos.

Con respecto a las telas, la Ley de Aduanas de 1835 marcó un cambio en el arancel establecido a la importación de textiles y otras manufacturas derivadas de la lana, lo cual benefició a las artesanías de Córdoba y Santiago del Estero: "Pero otros productos de las provincias no recibieron una protección similar. Fue el caso de la mayoría de las telas, cuya importación se mantuvo por preferencia de los sastres de Buenos Aires" (Katz, 2017, p. 22). Así es como podemos ver que la variedad de géneros, como los que predominan en la colección de indumentaria femenina, siguieron proviniendo de Europa.

Lamentablemente, en la colección del museo no contamos con ningún tipo de prenda interior como comúnmente se utilizaban bajo estos vestidos, ya sean camisas, enaguas, u hombreras para rellenar las mangas. Para el caso de la indumentaria femenina de las mujeres de Córdoba, Cecilia Moreyra indica a partir del análisis de inventarios post mortem que mayormente se usaban camisas y enaguas realizadas en géneros de fibra vegetal como lino y cáñamo y, en menor medida, algodón. Agrega que estos paños “(...) se desgastaban notablemente con el uso diario por lo que a su término había que adquirir retazos de tela para hacer nuevas prendas o bien, usar las enaguas y camisas hasta que fueran casi inservibles" (Moreyra, 2017, p. 506). Esta cuestión explica, en gran parte, la fragilidad del material frente al uso y el paso del tiempo, y, por lo tanto, su esperable ausencia en los depósitos de los museos.

Anuario de la Escuela de Historia Virtual - Año 11 - N 18 - 2020: pp. 69-106. ISSN: 1853-7049 
Otra prenda emblemática de la colección del MHN es el denominado en la institución como "corselete" que perteneció a Manuela Rosas," realizado en terciopelo de seda con escote tipo bote. Esta prenda fue inmortalizada en el retrato que realizó Prilidiano Pueyrredón, donde viste una bata junto con una falda con volados de encaje y moños. La elección del color responde al uso generalizado de prendas rojo punzó de la época, como símbolo de adhesión al gobierno de su padre, el gobernador Juan Manuel de Rosas. Hoy presenta una gran decoloración que ya se menciona en el catálogo para la Exposición del traje en el Río de la Plata, desde el siglo XVII hasta el siglo XX realizada en 1969 en el que dice: "Color: era rojo, está desteñido en color avellana" (Asociación Amigos de los Museos Histórico Nacional y del Cabildo, 1969, p. 27). Además de haberse exhibido en esa oportunidad, por años se encontró en la Sala Rosas, en una vitrina alargada junto a otros objetos, como se evidencia en una fotografía de 1939, y formó también parte de la primera exposición del Museo del Traje.

\section{Figura 6. Anónimo, Retrato de Petronila Menchaca y San Martín}

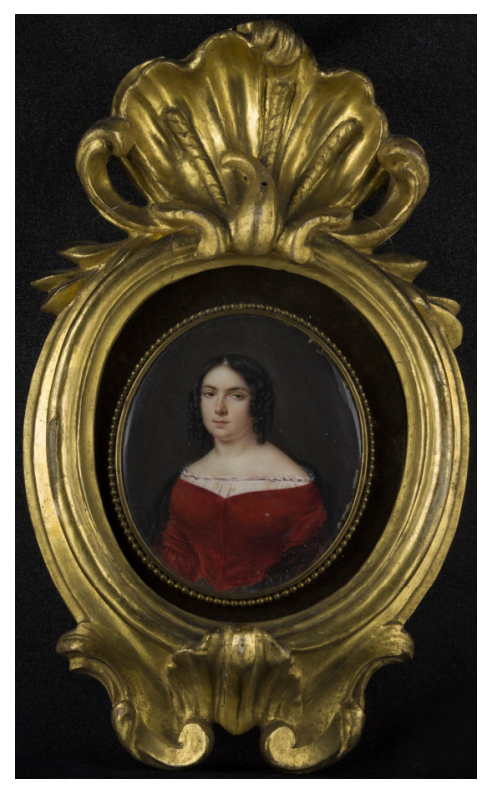

Fuente: Museo Histórico Nacional, Buenos Aires. Número de inventario: 1300.

\footnotetext{
${ }^{6}$ Hija de Juan Manuel de Rosas y Encarnación Ezcurra. Nacida en Buenos Aires el 24 de mayo de 1817. Luego de fallecida su madre, Manuelita comienza a cumplir funciones de anfitriona y colaboradora de su padre; por su personalidad, logró la adhesión de quienes la trataban, rodeándose de un círculo íntimo de confianza, ocupó muchas veces el lugar de intermediaria entre su padre y las partes. Así, su figura adquirió un relieve que el romanticismo de la época acentuó hasta hacer de ella un símbolo.

Luego de finalizados los gobiernos de su padre, se casó con Máximo Terrero, con quien tuvo dos hijos: Manuel Máximo, en 1856, y Rodrigo Tomás, en 1858. Vivió en Londres, desde donde visitaba a su padre. Murió en esa ciudad el 17 de septiembre de 1893, sin haber regresado a su patria.
} 
Figura 7. Pueyrredón, Prilidiano, Retrato de Manuelita Rosas, 1851

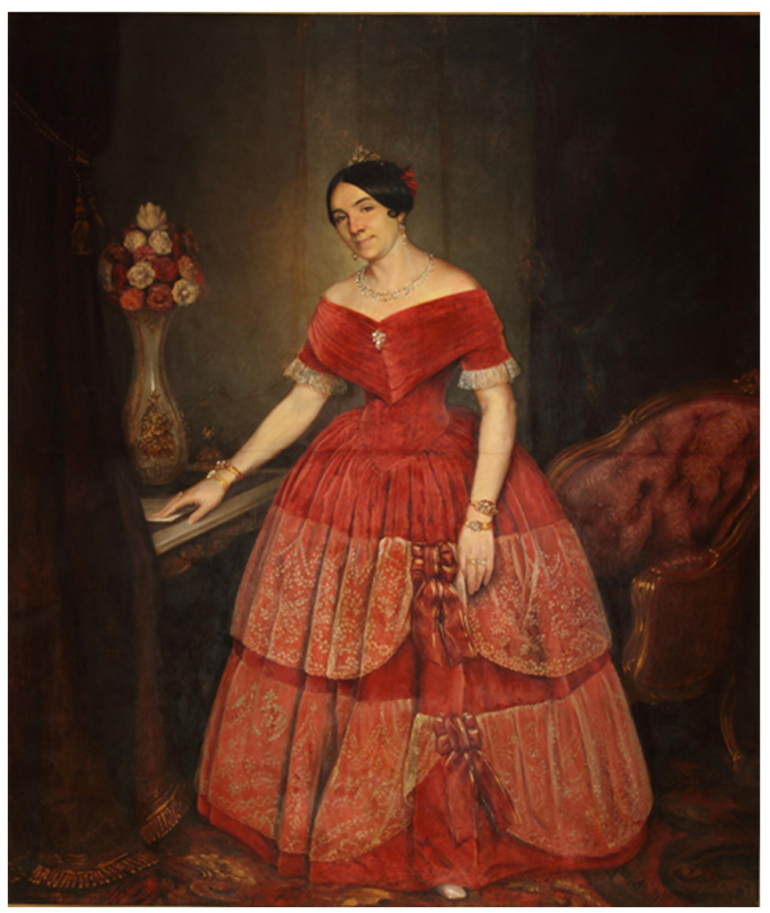

Fuente: Museo Nacional de Bellas Artes., Buenos Aires. Número de inventario: 3188.

Figuras 8 y 9. Corselete de Manuelita Rosas, anverso y reverso

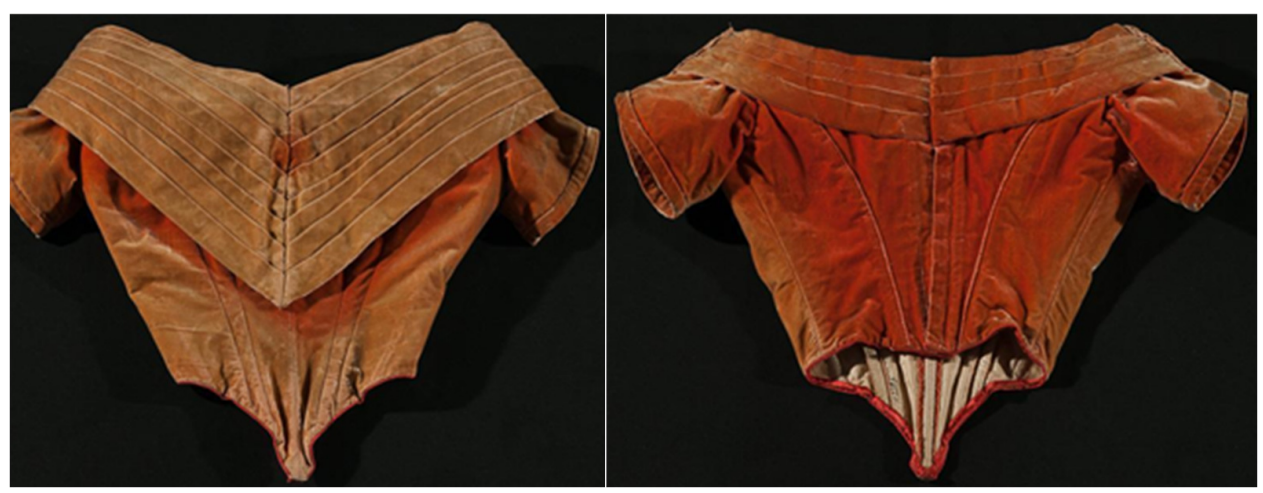

Fuente: Museo Histórico Nacional, Buenos Aires. Número de inventario: 2395.

Además, se conservan en la colección del museo otros textiles que pertenecieron a Manuela: una caja de vestidos bordada, fragmentos de raso de seda bordados con hilos metálicos, una cinta y una capa, ingresada al museo como "salida de teatro". 
Figura 10. Sala Rosas, 1939. Vista general

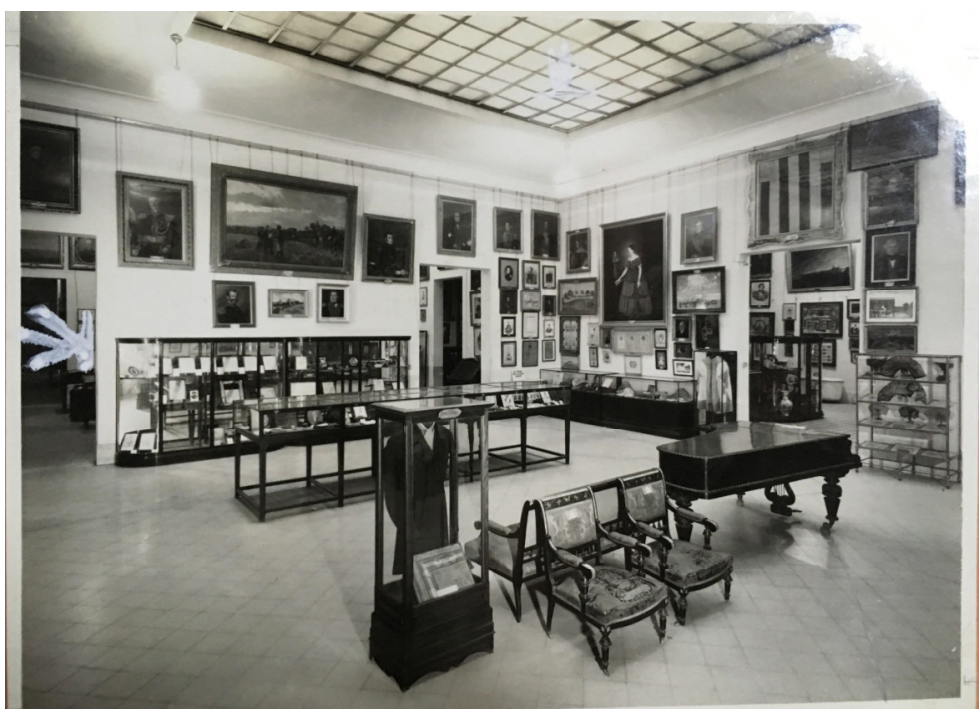

Fuente: El Museo Histórico en su Cincuentenario 1889-1959. Buenos Aires, Peuser, p. s/n.

Figura 11. Sala Rosas, 1939, detalle

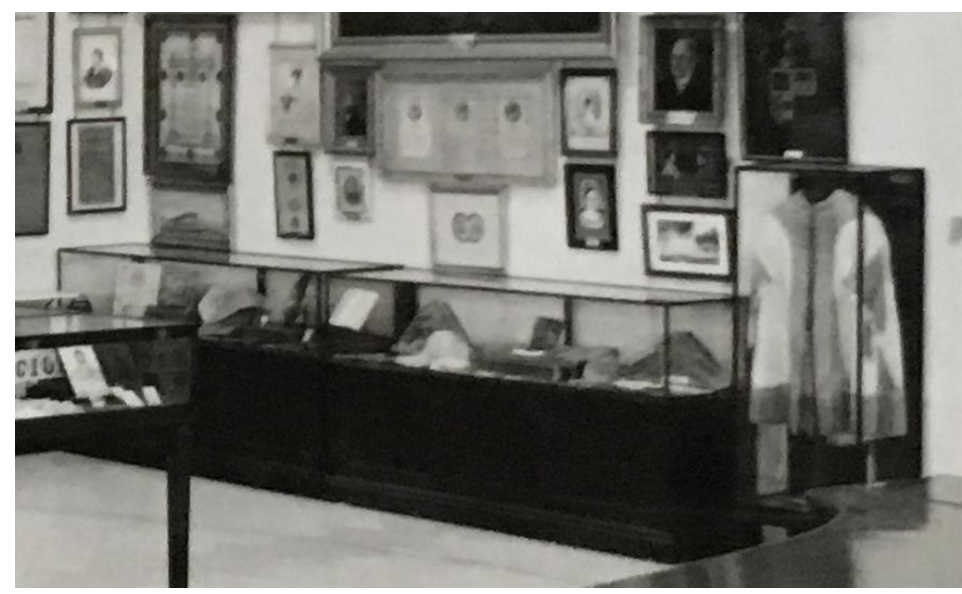

Fuente: El Museo Histórico en su Cincuentenario 1889-1959. Buenos Aires, Peuser, p. s/n.

En la fotografía anterior, en la vitrina alargada, podemos observar el corselete y en la vitrina de pie, la denominada salida de teatro.

\section{Chales, mantones y mantillas}

Resultaba indispensable para la mujer del siglo XIX contar con un elemento que le ayudara a completar el atuendo y le sirviera para cubrir hombros, cabeza y pecho. Esta costumbre de raigambre española se hizo extensiva a las mujeres de la elite local, como se 
evidencia en distintos relatos de viajeros y fuentes iconográficas -como las litografías de Emeric Essex Vidal- en los que se destaca el uso de chales, mantos y mantillas como elemento distintivo de la moda local.

\section{Figuras 12 y 13. Vidal, Emeric Essex, Iglesia de Santo Domingo}
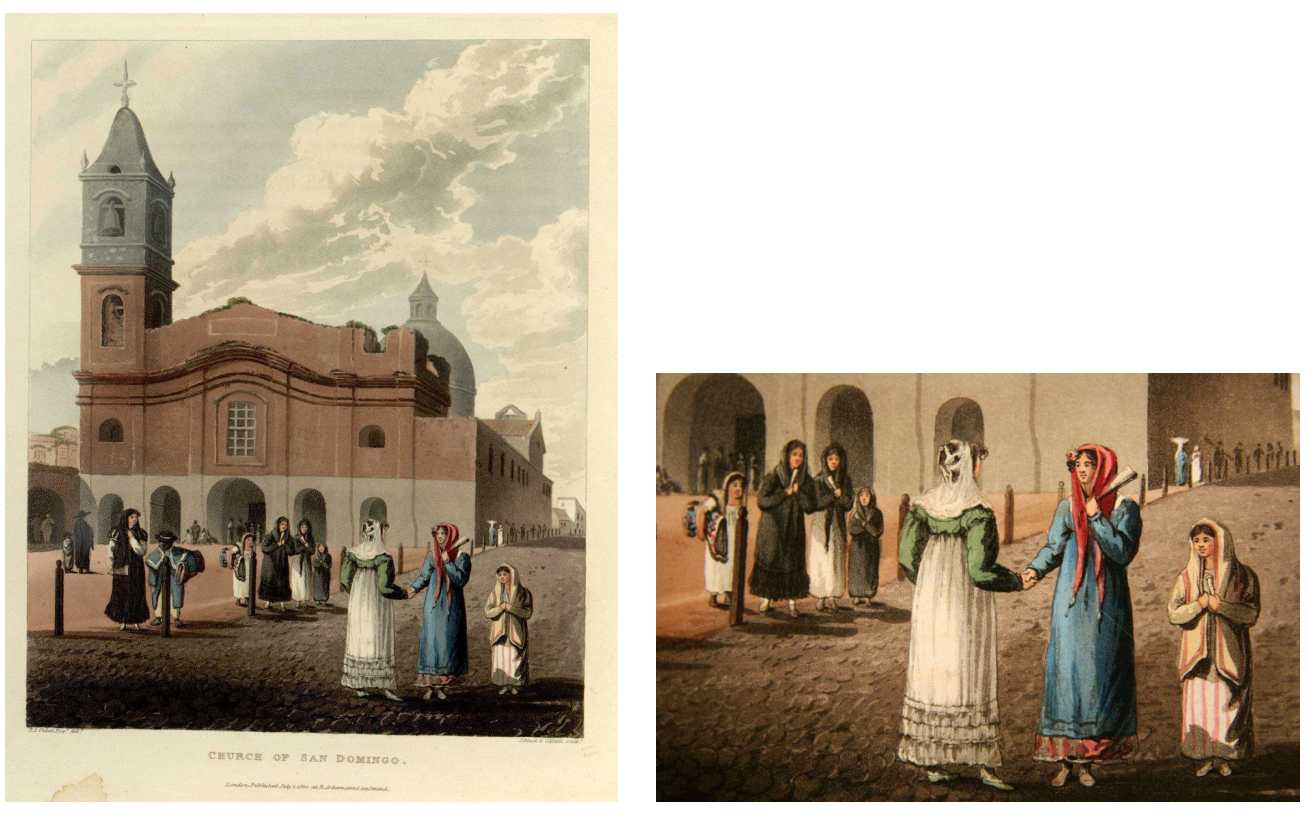

Fuente: publicada originalmente en Londres en 1820. Reproducido en Moores, “Estampas y vistas de la Ciudad de Buenos Aires (1599-1895)”. Buenos Aires, Peuser, 1945.

En el MHN contamos con piezas de la época que nos permiten saber cómo eran esas prendas, de qué materiales estaban hechas y quiénes las usaban. Sin embargo, hay que tener en cuenta que los textiles que llegaron a ser parte de las colecciones de nuestro museo responden a un sector reducido de la sociedad y, por lo tanto, no es posible contar con prendas que den cuenta de cómo vestían y cubrían las mujeres de los sectores populares.

Las prendas de encaje de Carmen Larraín y Aguirre ${ }^{7}$ formaron parte de un vestido de boda que utilizó al unirse en matrimonio con Juan Gregorio de Las Heras, en Santiago de Chile en el mes de marzo de 1820. Casi 120 años después fueron donadas al museo por sus nietas, Elena y Carmela de Las Heras, quienes previamente se habían contactado por carta con el entonces Director del museo, el Sr. Federico Santa Coloma. Allí, mencionaban la intención de enviar desde el país vecino objetos de su abuelo, como un sillón “y los

\footnotetext{
${ }^{7}$ Fue miembro destacado de la elite chilena. Esposa del General Gregorio de Las Heras, con quien tuvo cinco hijos. Nieta de Martín José de Larraín (1718-1770), patriarca y jefe del "Clan de los Ochocientos", un grupo de actuación política durante la revolución e hija de Martín de Larraín y Salas (1756-1835), célebre patriota y Josefa de Aguirre y Boza Andía-Yrarrázabal, IVa Marquesa de Montepío y Señora del Mayorazgo Aguirre.
} 
encajes de Inglaterra que le regaló San Martín a nuestra abuelita" ${ }^{8}$ Continuando con este intercambio epistolar, en una carta dirigida al museo y fechada el 27 de junio de 1939, Ema R. Boccard, esposa del Cónsul argentino en Chile, escribe:

(...) también tengo que felicitarlo por los encajes y otros objetos de gran valor que llevaremos junto con las Stas. Las Heras, en septiembre u octubre, en nuestro proyectado viaje, a esa; yo me comprometo a persuadirlas para el viaje en esa fecha y espero en Dios que no tendremos inconvenientes, pues deseosa, como estoy que estos encajes tan valiosos en su valor histórico han de llegar pronto a sus manos. Son maravillosos y como usted sabe pertenecieron al traje de boda, regalo del Gral. San Martín a la esposa del General, que fue padrino del matrimonio y el valioso velo de tres puntas de encaje de Inglaterra, es una reliquia de gran valor y que será de gran admiración para su museo. -Todas estas piezas están maravillosamente conservadas- .9

Efectivamente, en la actualidad, aún presentan un buen estado de conservación, cuestión poco habitual en otras prendas, donde los deterioros ocasionados por el uso y el envejecimiento de los materiales son varios. Este hecho destaca -más allá de su historia y devenir dentro del museo- que los familiares que atesoraban estos objetos cumplieron una primera función de conservación de los mismos, tan válida como la que realizamos hoy en día, dado que, gracias a ese cuidado primigenio, hoy pueden ser parte de nuestras colecciones. Puntualmente, los encajes, que habrían pertenecido a la vestimenta de boda de Carmen Larraín y Aguirre, son de algodón y se conforman de una mantilla, un chal, un fragmento -que suponemos podría haber sido parte de la falda-, un cuello y ambos puños del vestido. Debemos mencionar que los motivos de los encajes son en su mayoría florales y no se repiten de una pieza a la otra.

Una sexta prenda completa el patrimonio de la mujer y se trata de un mantón de seda de los denominados de "Manila", que presenta no solo un gran atractivo visual por los colores y diseños empleados, sino también por la sobresaliente labor de bordado realizada íntegramente a mano con hilos de seda.

\footnotetext{
${ }^{8}$ Carta de Elena y Carmela Las Heras a Santa Coloma, Buenos Aires, 22 de junio de 1939. AH MHN, FG, Caja 27, Exp. 3, letra L.

${ }^{9}$ Carta de Ema R. Boccard a Santa Coloma Brandzen (sic), Buenos Aires, 27 de junio de 1939. AH MHN, FG, Caja 27, Exp. 3, letra L.
} 


\section{Figura 14. Durand, Carlos, Retrato de Javiera Carrera de Díaz Vélez, 1821}

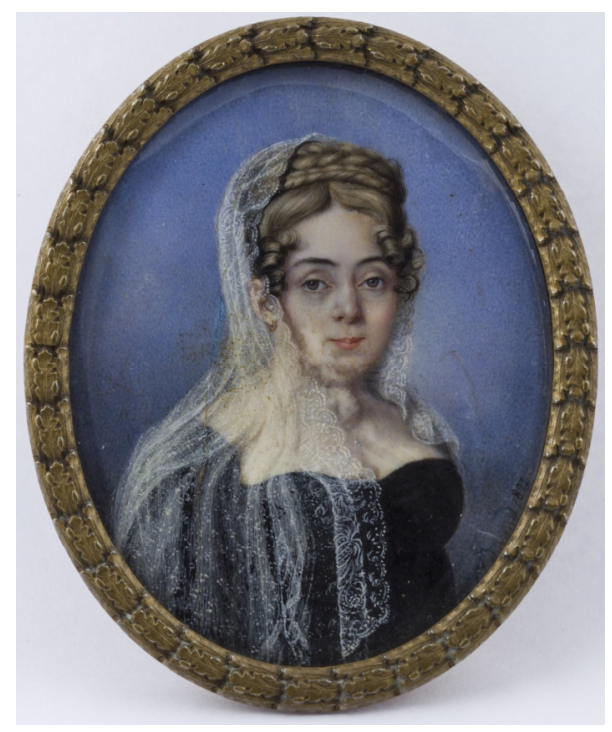

Fuente: Museo Histórico Nacional, Buenos Aires. Número de inventario: 4637.

\section{Figura 15. Mantón de Carmen Larraín y Aguirre de Las Heras}

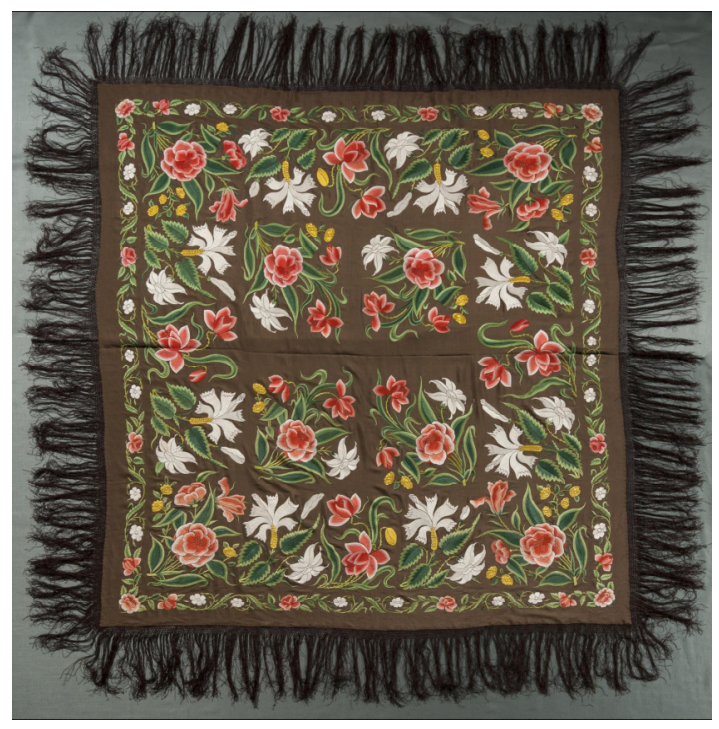

Fuente: Museo Histórico Nacional, Buenos Aires. Número de inventario: 1590. 
Otro dato a destacar es que, según los legajos de estas prendas, ${ }^{10}$ todas ellas fueron exhibidas en la Sala Las Heras y Lavalle durante gran parte del siglo XX, nuevamente quedando las piezas femeninas supeditadas a los "grandes hombres" de la patria, en este caso el marido de Carmen. En la siguiente fotografía podemos observar los encajes expuestos en una vitrina.

Figura 16. Fotografía de la Sala Las Heras - Lavalle, julio de 1967

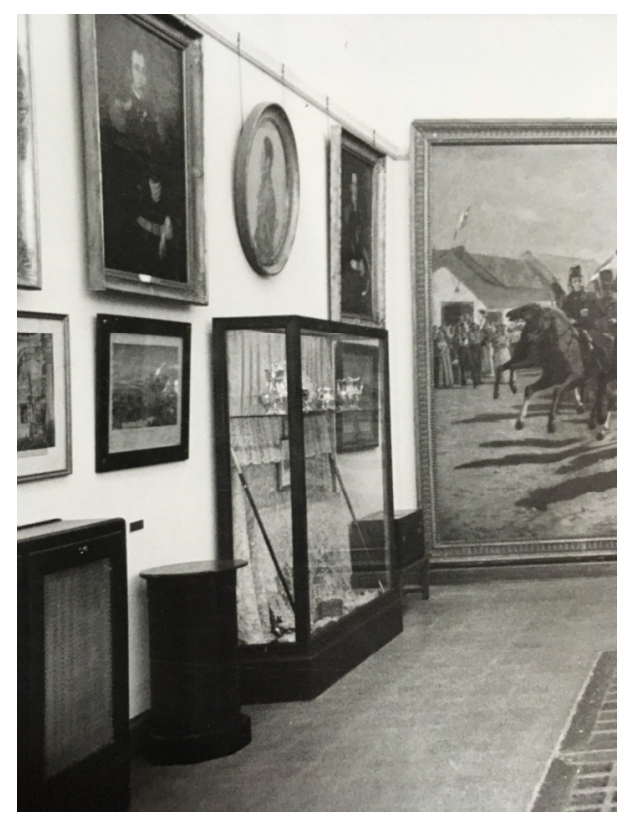

Fuente: AHMHN, Fondo Institucional, Carpeta de fotografías de salas de exposición del MHN.

En esta categoría también nos ocupamos del análisis de otras prendas de Manuela Rosas, en este caso dos chales de seda bordado, uno de ellos con láminas metálicas y el otro con hilo de seda color rojo. También contamos con fragmentos de encaje que habrían pertenecido a la familia, puntalmente a Teodora Arguibel de Ezcurra ${ }^{11}$-abuela materna de Manuela-, pero debido a su avanzado estado de deterioro no fue posible hacer una lectura del textil.

Junto con los vestidos de Bernardina Chavarría mencionados en el apartado anterior, se donaron dos chales y dos mantillas, hecho que grafica su nieto de puño y letra asegurando que: "Cada traje lleva la correspondiente pañoleta". ${ }^{12} \mathrm{Al}$ no diferenciar el donante

\footnotetext{
${ }^{10}$ Legajos MHN 1578, MHN 1585 A, MHN 1585 B, MHN 1587, MHN 1588 y MHN 1590. Área de Registro y Documentación de las colecciones. Museo Histórico Nacional, Buenos Aires.

${ }^{11}$ De padre francés, nace en Buenos Aires el 11 de septiembre de 1763 y muere en la misma ciudad en 1846. Se casa un 13 de enero de 1783 con Juan Ignacio de Ezcurra Ayerra, con quien tiene 9 hijos, entre las que se encuentra Encarnación Ezcurra, esposa de Juan Manuel de Rosas y madre de Manuela Rosas.

${ }^{12}$ Carta de Eduardo Dudignac Mansilla dirigida a José Pérez Valiente de Moctezuma, Buenos Aires, 10 de marzo de 1924. AH MHN, FG, Caja 3, Documentos de donación, Libro XXI, Carpeta 1924, número de orden $8 / 2$.
} 
de forma específica la vinculación existente entre las prendas, resulta poco probable otorgar una relación directa entre cada una de ellas, sumado a que, en líneas generales, eran usadas indistintamente con un vestido u otro, salvo en los casos que se guardara luto. Más allá de esta salvedad, cabe mencionar que en el museo fueron exhibidas en la sala Damas Patricias sobre los maniquíes que servían de soporte para los vestidos.

Figuras 17 y 18. Mantilla de Bernardina Chavarría de Viamonte

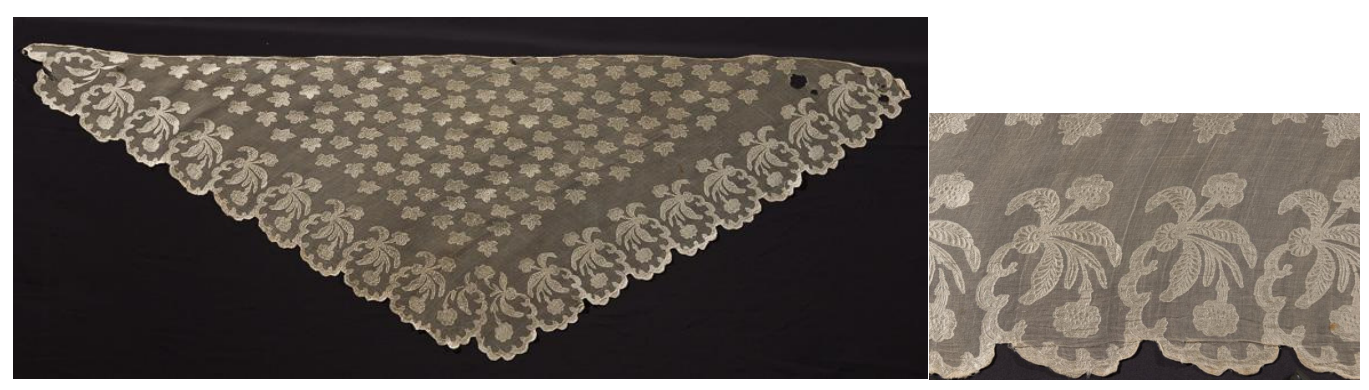

Fuente: Museo Histórico Nacional, Buenos Aires. Número de inventario: 4623.

Figura 18. Goulu, Jean Philippe, Retrato de la señora

Lucía Petrona Riera de López, 1827

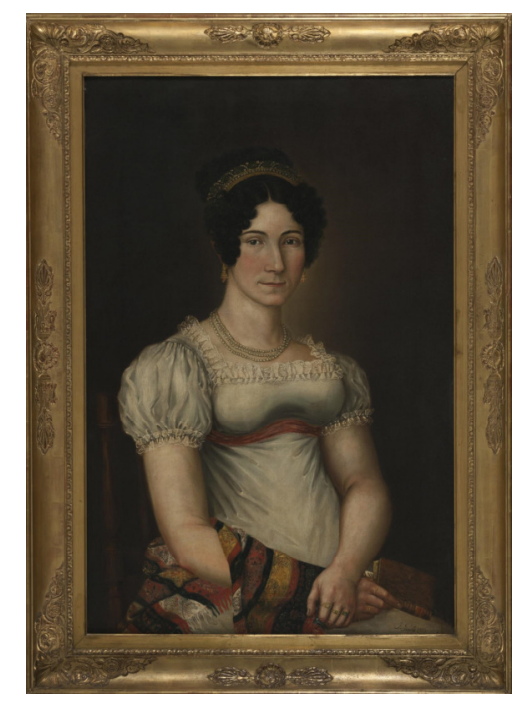

Fuente: Museo Histórico Nacional, Buenos Aires. Número de inventario: 3065. 
También contamos dentro de la colección con un chal occidental (probablemente francés) de imitación de cachemira, ${ }^{13}$ que perteneció a María Muñoz de Villanueva, ${ }^{14}$ realizado con diseños de inspiración islámica como flores y arabescos. En la carta de donación del 17 de febrero de 1950, dirigida al Director del MHN Antonio Apraiz, la Sra. Asíndila del Valle de de Pol justifica los motivos por los cuales desea donar esta pieza, mencionando la relación de su familia con hechos y hombres de nuestra historia:

Tengo el agrado de dirigirme á Ud. para ofrecer á ese Museo un mantón de Cachemira de la India tejido en tela á mano de lana y seda y mide tres metros por uno y medio. Data de antes de 1850 y perteneció á mi bisabuela María Muñoz de Villanueva esposa de José Antonio de Villanueva mendocino que se estableció en campos de la provincia de Buenos Aires que atravesó luego el ferrocarril y á cuya estación se puso el nombre de Villanueva.

También fué pariente cercano del Alcalde de primer voto Don Miguel de Villanueva que en las invasiones de 1806 tomó una bandera á los ingleses y fué íntimo amigo de Don Martín de Alzaga (...)

Estos datos se los doy Señor Director con el único objeto de esclarecer el ofrecimiento de lo que para mi es una reliquia que hé heredado y que creo tiene valor de tradicion. Cuando se inauguró el actual Cabildo ofrecí dicho mantón para el museo pero el Dr. Cárcano (Ramon) presidente de la comision me contestó que no podian aceptarlo porque solo habia objetos que tuvieron relacion directa con el Cabildo pero que seria espléndido son sus palabras, para el Museo Histórico y me pedia que lo donase.

Cumplo ahora con el deseo que tengo de entregarlo donde pueda conservarse por siempre..$^{15}$

Resulta interesante destacar que esta es la última pieza textil relacionada con una mujer que ingresa a la colección del MHN, después de ser desestimada su incorporación al Museo del Cabildo.

\section{Accesorios}

La indumentaria femenina de la primera mitad del siglo XIX se complementaba con una serie de accesorios que pretendían no solo resaltar la apariencia de la mujer o satisfacer necesidades utilitarias, sino también cumplir funciones fundamentales relacionadas con los tiempos que se vivían, siendo depositarios de identidad, posiciones políticas y transmisores de códigos culturales.

\footnotetext{
${ }^{13}$ Dato extraído de las apreciaciones de la investigadora del Museo de la Historia del Traje, Lic. Delia H. Etcheverry.

${ }^{14}$ Nace en 1790 y muere en 1858. Estaba casada con José Antonio Villanueva Avaria, con quien tuvo 13 hijos. Su suegro fue José Antonio Villanueva Godoy, un abogado radicado en Buenos Aires que participa de la defensa y reconquista de la ciudad durante las Invasiones Inglesas, llegando a ser capitán del Batallón de Arribeños y años más tarde, en 1812, diputado por Mendoza.

${ }^{15}$ Carta de donación de Asíndila del Valle de Avarua Pol al Director del MHN Antonio Apraiz, Buenos Aires, 17 de febrero de 1950. AH MHN, FG, Caja 44, Exp. 1 y 2, letra V.
} 
Escribía un viajero francés que pisó las costas de Buenos Aires en el año 1827 que el abanico era una "especie de cetro que jamás abandona una porteña" (Leonardi y Vaisman, 2017, p. 60), graficando lo extendido que estaba su uso, no solo para soportar los calores de verano, sino también para establecer, por medio de su empleo, una suerte de lenguaje no verbal, donde se comunicaban cuestiones vinculadas a lo sentimental. Este código implicaba que la mujer cerrara o abriera el abanico de determinadas formas, acercándolo a distintas partes del cuerpo para transmitir el mensaje deseado, como relata otro viajero: “En los movimientos hechiceros de esta arma formidable, revelan ellas un talento sin rival. Con el abanico pueden despertar o repeler una pasión; pueden avivarla como apagarla; en resumen, el abanico no hace otra cosa que hablar: en el baile, en el teatro, y hasta diría, en la iglesia" (Leonardi y Vaisman, 2017, p. 42).

La colección de abanicos del MHN presenta una notable variedad de materiales y técnicas, como filigrana, papel impreso, pintura sobre marfil, carey calado, encaje y telas bordadas. Gran parte contiene escenas impresas o dibujadas a mano sobre el país, que por lo general tienen a la mujer como protagonista, estando en grupo o cortejadas por algún hombre, motivo comúnmente usado en las denominadas escenas galantes. En uno de ellos, donado por José Pérez Valiente de Moctezuma en 1938, se representan pasajes bíblicos relacionados con Ruth.

En otros abanicos se encuentran representadas obras realizadas por Carlos Enrique Pellegrini, como "Minuet", que retrata un baile en una tertulia, y "Porteñas de 1831", con tres mujeres sentadas tomando mate. Otro, de varillaje de madera, presenta el dibujo de la obra de Juan León Palliere “Cazuela del Teatro Colón” de 1863, donde curiosamente la mayoría de las retratadas se encuentra con un abanico en la mano, señalando que el uso de este accesorio se prolongó entrada la segunda mitad del siglo XIX.

Uno de los abanicos emblemáticos de la colección es el que perteneció a Laureana Ferrari de Olazábal, ${ }^{16}$ del que se quitaron algunas lentejuelas para bordar la bandera del Ejército de los Andes, como afirma la donante, Ana de Olazábal, en una carta escrita al director del Museo el 2 de marzo de 1898:

Tengo la satisfacción de donar ál establecimiento á su cargo el abanico que perteneció á mi señora madre Laureana Ferrari de Olazábal, una de las niñas mendocinas que bordó la bandera del ejército de los Andes, á la que pusieron las lentejuelas y piedras que en él faltan.

\footnotetext{
${ }^{16}$ Nació el 4 de julio de 1803, hija de Joaquín Ferrari y María del Rosario Salomón, mendocinos que colaboraron y adhirieron a la causa del Ejército de los Andes. Se casó en 1819 con Manuel de Olazábal, un oficial del Ejército Libertador, siendo el padrino de bodas y de su primogénito el Gral. San Martín. Colaboró en la confección de la bandera del Ejército de los Andes junto con Dolores Prats de Huisi, Remedios de Escalada, Margarita Corbalán y Mercedes Álvarez Morón. Dicha bandera la confeccionaron en su casa, empezándola luego de la Navidad de 1816 y terminándola el 5 de enero de 1817. Falleció en Buenos Aires el 6 de septiembre de 1870.
} 
Dicho objeto conservó mi madre con religioso cuidado hasta su fallecimiento el 6 de Septiembre de 1870 y como vino a mi poder, he creido que es una prenda digna de guardarse junto á las reliquias de la época gloriosa de nuestro país. ${ }^{17}$

En una carta de la misma Laureana dirigida a su esposo, el coronel Manuel de Olazábal, en 1856, relata los pormenores de la confección de la bandera y menciona a los abanicos usados para extraer las lentejuelas:

Inmediatamente Remedios se puso a coser la bandera, mientras nosotros preparábamos las sedas y demás menesteres para bordar, de dos de mis abanicos sacamos gran cantidad de lentejuelas de oro, de una roseta de diamantes de mamá sacamos varios de ellos con engarce para adornar el óvalo y el sol del escudo, al que pusimos varias perlas del collar de Remedios. ${ }^{18}$

Efectivamente, a partir de la observación del abanico identificamos que se encuentra bordado con lentejuelas y aplicaciones de metal plateado y dorado que conforman un diseño floral. En cuatro sectores detectamos faltantes de lentejuelas doradas de dos tipos, unas planas y otras en relieve más pequeñas. Al retirarlas quedaron al descubierto los hilos sueltos que las sujetaban y el dibujo que se realizó previamente para el bordado, convirtiéndose en un testimonio visual de cómo se realizaban estos trabajos.

Figuras 20, 21 y 22. Abanico de Laureana Ferrari de Olazábal

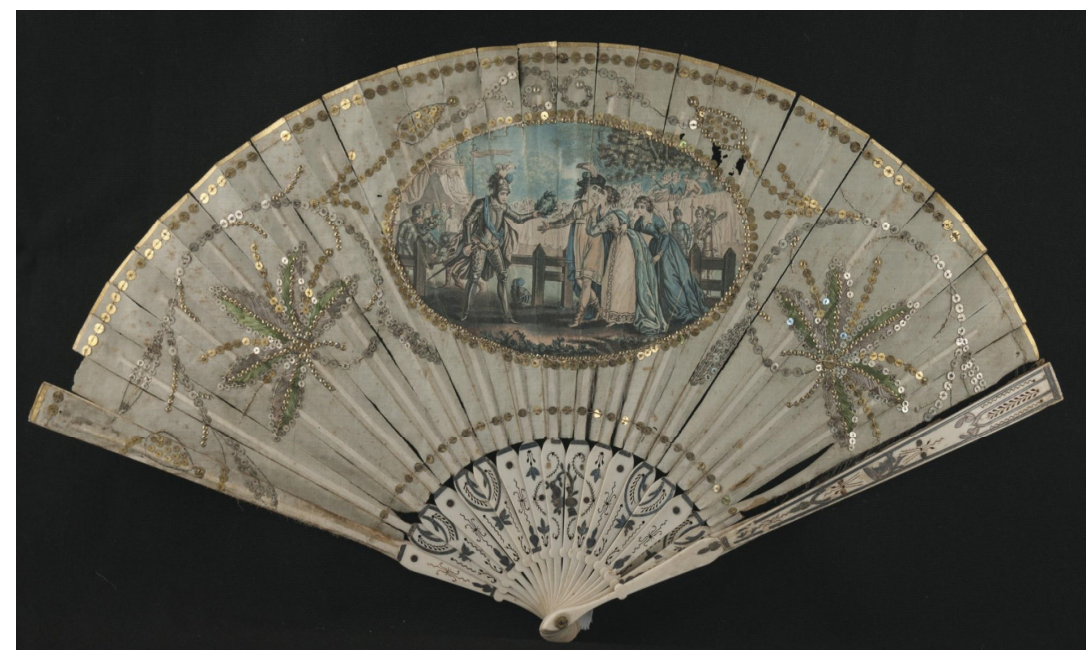

\footnotetext{
${ }^{17}$ Carta de donación de Ana de Olazábal al Director del Museo, Buenos Aires, 2 de marzo de 1898. AH MHN, FAPC/FGF, Libro de Donación N 5, folio 196.

${ }^{18}$ Carta de Laureana Ferrari de Olazábal a Manuel de Olazábal, Buenos Aires, 30 de noviembre de 1856. AGN, Sala 7. Museo Histórico Nacional. Legajo 28. Documento 3402.
} 


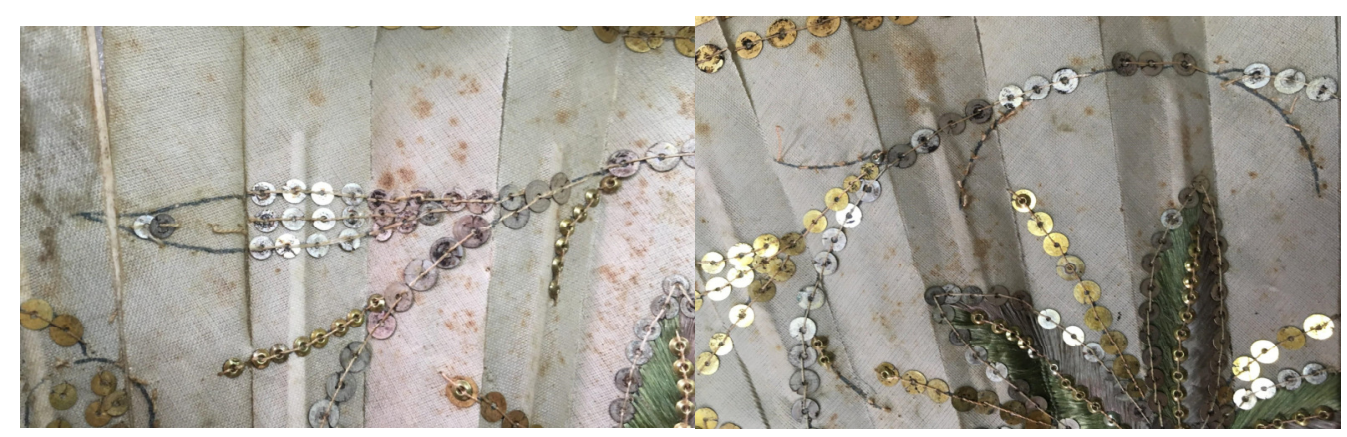

Fuente: Museo Histórico Nacional, Buenos Aires. Número de inventario: 1233.

Existe, además, una singular serie de tres abanicos realizados posiblemente para conmemorar la creación del Himno Patriótico. El país es de papel con un impreso coloreado a mano, con el busto de Vicente López y Planes, rodeado por nubes, ramos, guirnaldas, banderas argentinas, el escudo nacional y la letra del Himno, en nueve estrofas. Solo contamos con datos de uso y pertenencia de dos de ellos, siendo uno de María Agueda Monge de Perdriel ${ }^{19}$ y el otro de la Señora Riera de Navarro. Este último fue ingresado al museo en el año 1899, asentándose en el Libro de Registro del MHN como un "abanico mandado hacer en Europa en 1830 por el Sr. D. Mariano Lozano" ${ }^{20}$

Figura 23. Abanico del Himno Patriótico

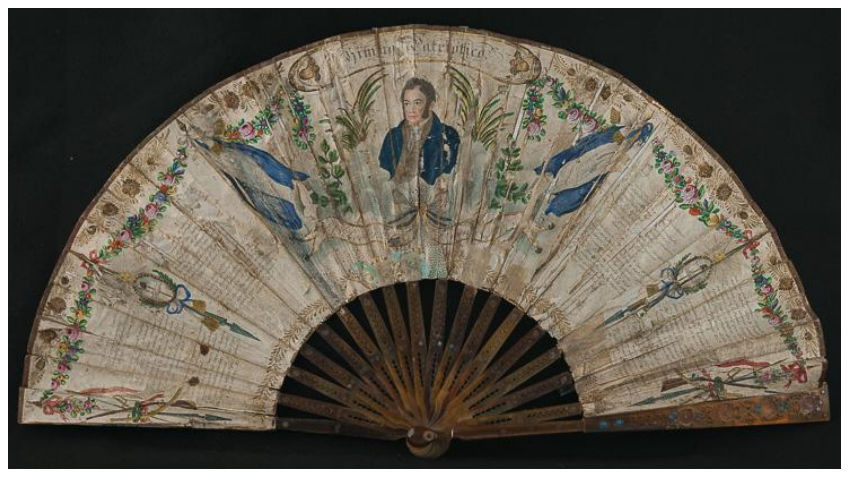

Fuente: Museo Histórico Nacional, Buenos Aires. Número de inventario: 3042.

Falta mencionar otros dos abanicos de la colección, uno de ellos realizado con encaje de algodón color blanco y varillas de nácar, que perteneció a Carmen Larraín, y otro de

\footnotetext{
${ }^{19}$ Nació en Buenos Aires el 7 de febrero de 1788, hija de Facundo Monje y Bello y de María Josefa Laforet. Se casó el 22 de julio de 1811 con Gregorio Ignacio Perdriel, un militar que participó de las Invasiones Inglesas y la Guerra de la Independencia.

${ }^{20}$ AH MHN, Libro de Registro N²1, folio 72, número de orden 1331, 1 de diciembre de 1899.
} 
filigrana esmaltada que ingresa junto a los textiles donados por Eduardo Dudignac Mansilla. Resulta interesante reparar una vez más en los trabajos de decoración de estas piezas que se lograban con diferentes técnicas como incrustaciones, tallas y delicados calados que tenían tanto las varillas y padrones, como el país y que se repiten en otras piezas pertenecientes a las mujeres.

Figura 24. Abanico de filigrana

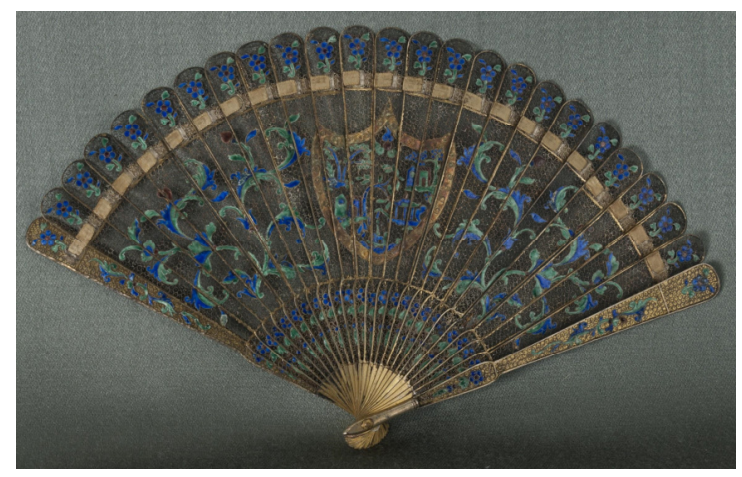

Fuente: Museo Histórico Nacional, Buenos Aires. Número de inventario: 4617.

En otro de los objetos donde este tipo de trabajo encontró su máxima expresión es en los llamados peinetones, que se trataban de grandes piezas de carey caladas con intrincados diseños, que usaron mayormente las porteñas durante la década de 1830. Muchos de ellos hoy son parte de las colecciones de museos, como reflejo de una de las primeras manifestaciones de la moda local. Puntualmente en el MHN existen ocho peinetones que muestran distintas características, algunos son lisos, otros presentan una guarda superior y el resto posee gran parte de la superficie calada con diseños florales como si se tratase de un gran encaje. Por lo general, la forma es de un rectángulo curvado con bordes lisos, que en la parte inferior posee los peines que servían para sujetar la pieza al cabello, en intrincados peinados que podían completarse con la colocación de flores. 
Figura 25. García del Molino, Fernando. Retrato de Encarnación Ezcurra de Rosas, 1839

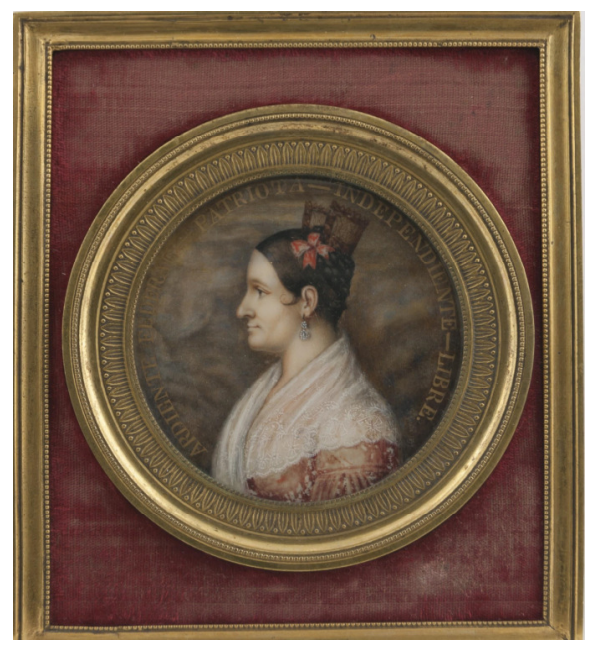

Fuente: Museo Histórico Nacional, Buenos Aires. Número de inventario: 2460.

La mayoría de estos peinetones y peinetas ingresan al museo en el año 1901 con la adquisición de la colección de Ángel Justiniano Carranza junto a otros objetos, sin especificarse mayores datos de uso o procedencia. Dentro de esta colección, se destacan dos peinetones de grandes dimensiones, siendo el más grande el que mide 60 centímetros de ancho y 35 de alto, que además posee hasta 16 dientes.

El peinetón llegó a presentar grandes controversias y se convirtió en un tópico ineludible, generador de intensos debates culturales. Regina Root señala que "en un momento en que el campo se enfrentaba a las angustias de la guerra civil, el tocado representaba una respuesta urbana y de género a la búsqueda de un espacio público (...) el peinetón llegó a ser sinónimo de la mujer que participaba en público y cuya presencia ya no podía ignorarse" (Root, 2014, p. 120). La mera presencia de las mujeres con peinetón en las calles generaba incomodidad a los hombres, que lo manifestaban, en primera instancia, por la molestia de tener que cambiar de dirección al caminar y, luego, por el gasto importante que implicaba para la economía familiar. La presencia que imponían las mujeres con sus peinetones en el espacio público hacía ineludible su existencia y rompía con la intención explícita de que las mismas se circunscribieran al mundo privado. La conjunción de las mangas jamón y los peinetones era representada como una moda incómoda, para los hombres claramente, no para las mujeres que la lucían, y tanto para unitarios como para rosistas, a pesar de que el peinetón era una manifestación en público del apoyo al régimen federal. 
Figura 26. Peinetón

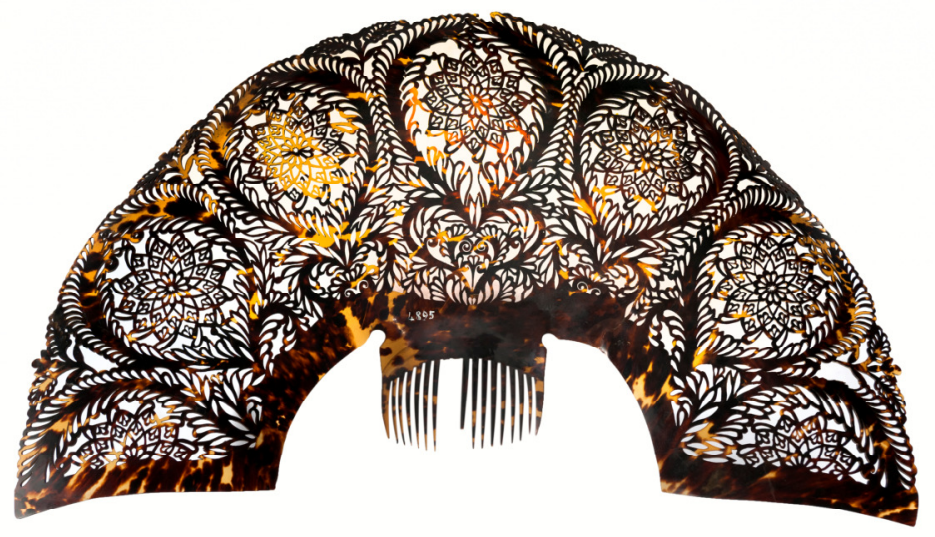

Fuente: Museo Histórico Nacional, Buenos Aires. Número de inventario: 4895.

En relación a las peinetas, las formas y materiales son más variados, empleándose no solo carey sino también cuerno de bovino para su fabricación, como en el caso de un ejemplar único de nuestra colección, que lleva la leyenda incisa y pintada en color rojo: “¡Viva la heroína de los federales!", "Soy hasta la muerte, firme, fiel y fuerte", haciendo clara referencia a Encarnación Ezcurra, la mujer del gobernador Juan Manuel de Rosas. Este fue un elogio comúnmente utilizado por los federales e inmortalizado en la obra literaria el Matadero de Esteban Echeverría, lo que resalta su papel como gran articuladora política de la época. Esta pieza es sin dudas única, ya que perteneció a una mujer simpatizante del rosismo, que mostraba de manera deliberada en la esfera pública su adhesión al partido federal y apoyaba, en particular, el accionar de una mujer, Encarnación Ezcurra.

Figuras 27 y 28. Peineta “¡Viva la heroína de los federales!”.

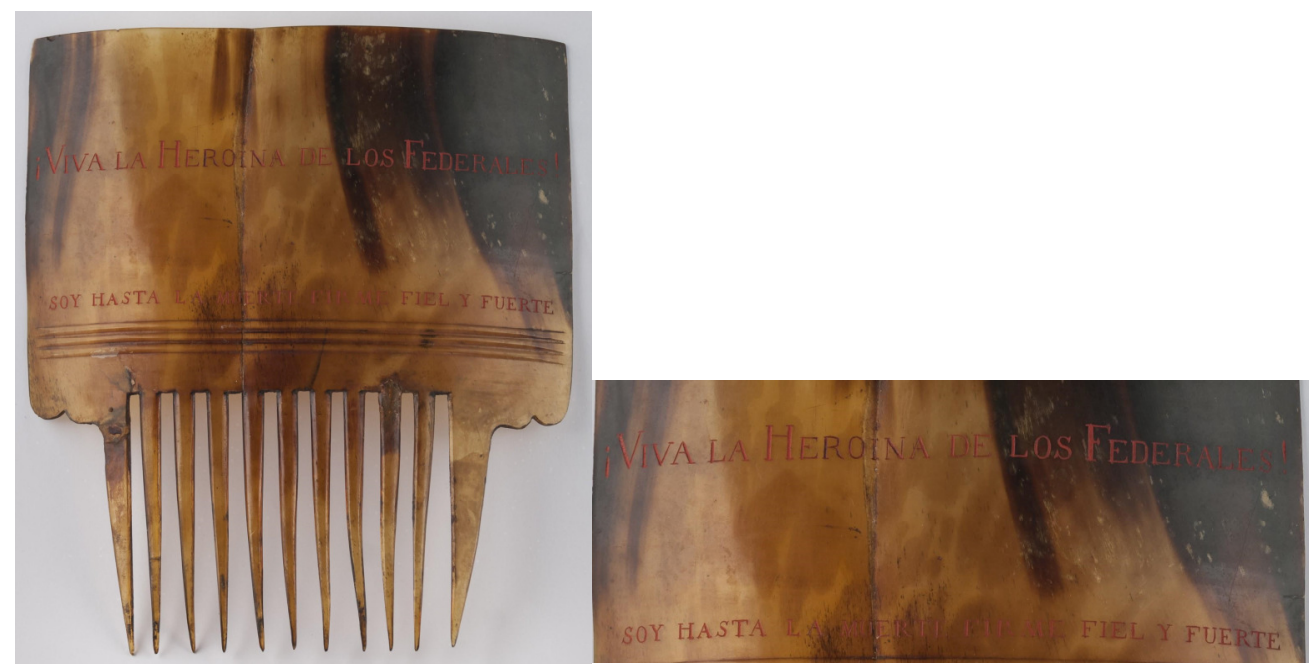

Fuente: Museo Histórico Nacional, Buenos Aires. Número de inventario: 2349. 
98 | Vestidas en la historia: una mirada a la colección de indumentaria femenina...

También era común en la época hallar la figura de Rosas impresa en abanicos o calada su efigie en los peinetones, como se evidencia en objetos presentes en el Complejo Museográfico Enrique Udaondo y el Museo Saavedra. En el museo existen otros accesorios que contribuían a crear la apariencia federal, como guantes de cabritilla con el busto de Rosas impreso y dos moños rojo punzó que las mujeres -niñas o adultas- debían llevar sobre el cabello del lado izquierdo.

Los pañuelos también eran objetos de uso habitual para las mujeres, en la colección hay tres pertenecientes a Manuela Rosas, María del Carmen Pineda y Dolores Urquiza. ${ }^{21}$ Este último presenta un caso especial dentro de la colección, dado que no solo hemos relevado información referida a su materialidad o la técnica empleada, entre lo que observamos que lleva escrito a mano con tinta negra en cursiva en una de sus esquinas el nombre "Lola Urquiza", sino también a su historia de uso. El mismo fue consignado en un listado dentro del legajo de una pieza de Urquiza, como el pañuelo con el "que su hija Lola enjugo la sangre de la herida que causó su muerte", 22 acontecida el 11 de abril de 1870 en el Palacio San José. De esta manera, este y otros objetos del museo fueron presentados desde un inicio como reliquias meritorias para narrar hechos relevantes para el país -que resaltaban a los grandes hombres de la historia-, y se diluía en la mayoría de los casos su valor como pieza de uso cotidiano perteneciente a una mujer. En el caso específico de este pañuelo, en el legajo, ${ }^{23}$ figura que durante parte del siglo XX fue exhibido en la Sala Urquiza.

El 19 de septiembre de 1822, José de San Martín, que era entonces Protector del Perú, les otorga a Serafina Hoyos de Arenales y a su hija Juana Antonia Arenales y Hoyos la "Divisa del Patriotismo", junto a los respectivos diplomas y dos bandas que son parte de la colección del MHN y que fueron donadas al museo por Serafina Martínez Arenales de Veyga el 5 de enero de 1907. Se trataría de los únicos objetos de la colección textil que evidencian una intención oficial de reconocer la labor de mujeres específicas, como puede haber sido la adhesión a la causa e, incluso, la realización de tareas de propaganda. Ambas fueron exhibidas en la sala Damas Patricias dobladas y enmarcadas junto al diploma.

\footnotetext{
${ }^{21}$ Nace en Concepción del Uruguay el 30 de abril de 1853, hija de Justo José de Urquiza y Dolores Costa. Se casa en 1873 con Samuel Pedro Sáenz Valiente, con quien tiene 6 hijos. Muere en Buenos Aires el 11 de enero de 1940.

${ }^{22}$ Legajo MHN 2955. Área de Registro y Documentación de las colecciones. Museo Histórico Nacional, Buenos Aires.

${ }^{23}$ Legajo MHN 3027. Área de Registro y Documentación de las colecciones. Museo Histórico Nacional, Buenos Aires.
}

Anuario de la Escuela de Historia Virtual - Año 11 - N 18 - 2020: pp. 69-106. ISSN: 1853-7049 
Figura 29. "Divisa del Patriotismo" del Perú, banda

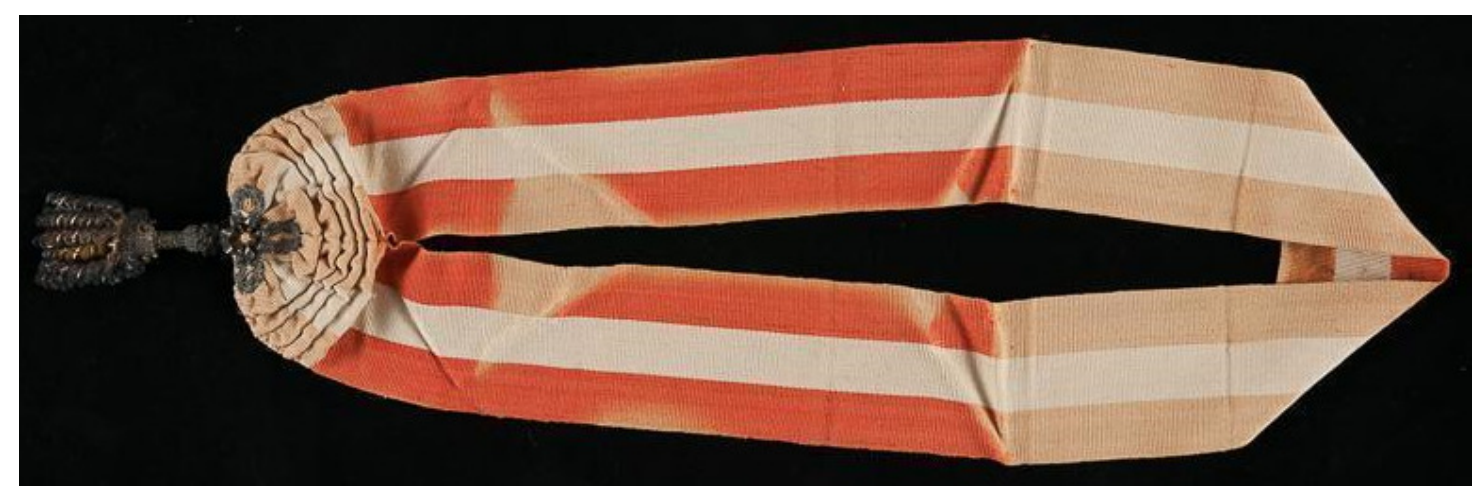

Fuente: Museo Histórico Nacional, Buenos Aires. Número de inventario: 4690.

Otro objeto que podría interpretarse como un signo explícito de la participación política de las mujeres en tiempos de guerra es una escarapela de tafetán de seda color violeta, que fue otorgada por el Mariscal López a la Comisión de Señoras, quienes fueron las encargadas de presentar el producto de la venta de las joyas de las damas paraguayas para los gastos de la Guerra del Paraguay, según consta en el Libro de Registros del museo. ${ }^{24}$

\section{Costura y confección}

Este último apartado surgió de la necesidad de abarcar aquellos objetos de la colección de textiles que no pertenecieron exclusivamente a mujeres, pero sí tenemos registro de que fueron realizados por ellas. A continuación, mencionaremos algunos ejemplos que dan cuenta de la cultura inmaterial contenida en tareas de bordado, costura, tejido o confección. Esto nos permitió rescatar los escasos nombres de las mujeres, encontrados en cartas de donación o en la misma pieza textil, y poner en valor un trabajo muchas veces ignorado. Aún gran parte del trabajo o autoría contenido en las piezas textiles del museo representa una gran incógnita, ya que existen muy pocas referencias a ello. En los contados casos en que lo hemos detectado, es muy común que se lo presente como un objeto realizado por una mujer, movida por el amor y devoción hacia los hombres de su familia o "la patria", entregado en muchos casos como "obsequio". Por ello, quedaban diluidas las referencias al verdadero trabajo que implicaba realizar esas piezas y la participación en los hechos que tenía esa mujer por medio de esos regalos.

Uno de los objetos que grafica lo antes dicho es la relojera que perteneció a José de San Martín. En una carta presente en el archivo histórico del museo, del 26 de mayo de 1926, Víctor Ferrari de Olazábal señala: “es una relojera bordada por mi abuela Laureana Ferrari y la Sa. Dolores Prats de Huisi quienes la regalaron al General San Martín el mismo día

\footnotetext{
${ }^{24}$ AH MHN, Libro de Registro N¹, folio 121, número de orden 1982, 7 de julio de 1905.
} 
que se juró la bandera de los Andes que ellas también bordaron" ${ }^{25}$ Lo curioso, además, es que posee forma de chinela y al parecer, según cuenta Manuel Olazábal, se habría realizado "del tamaño y medida de las chinelas usadas por Remedios de Escalada y San Martín la usó mientras pasaba en su casa y durante toda su estadía en Francia hasta su muerte después de la cual le fue devuelta a Laureana por Balcarce".${ }^{26}$ La relojera realizada por estas dos mujeres ${ }^{27}$ se exhibió por muchos años en la sala San Martín y, en la actualidad, se encuentra en el espacio expositivo denominado "Dormitorio", que se trata de la recreación de la habitación que el prócer habitó en Boulogne-sur-Mer.

Figura 30. Relojera de José de San Martín

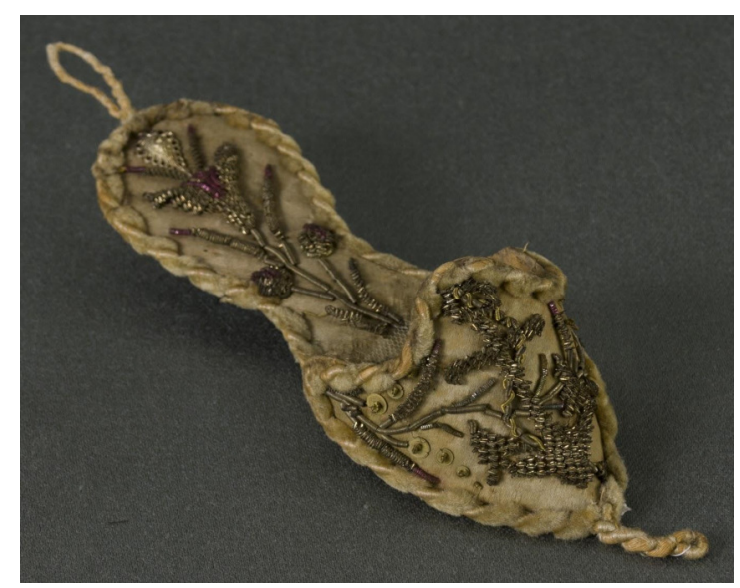

Fuente: Museo Histórico Nacional, Buenos Aires. Número de inventario: 1232.

Aquí, nos parece importante detenernos en el significado del bordado, entendido tradicionalmente como tarea femenina. Siguiendo los estudios de Rozsika Parker, la atribución de cualidades naturales a los cuerpos femeninos, para tareas tales como el bordado, puede ser identificada históricamente, así como el relegamiento del mismo como un arte doméstico. Este momento se identifica a partir del siglo XVI y, en consonancia con las ideas renacentistas, ansiosas por establecer la diferenciación sexual. Anteriormente, el bordado era principalmente realizado por

\footnotetext{
${ }^{25}$ Carta de Víctor Ferrari de Olazábal a Alfredo Munilla, Buenos Aires, 16 de mayo de 1926. AH MHN, FG, Caja 15, Exp. 8, letra M.

${ }^{26}$ Copia de carta de Manuel Olazábal del 6 de octubre de 1861, enviada por Víctor Ferrari de Olazábal a Alfredo Munilla el 26 de mayo de 1926. AH MHN, FG, Caja 15, Exp. 8, letra M.

${ }^{27}$ Laureana Ferrari de Olazábal, ver arriba.

Dolores Prats de Huisi era chilena, de Valparaíso, se encontraba refugiada en Mendoza luego de la Batalla de Rancagua, en la que muere su marido, un rico hacendado de Talcahuano. Luego del triunfo en la Batalla de Chacabuco, el 12 de febrero de 1817, decisiva para la Independencia de Chile, retorna a su tierra natal, donde falleció en 1834.
} 
hombres en las cortes. Así, el bordado pasaría a encarnar en ese momento una conjunción ideal entre feminidad y nobleza, aspirada para toda posible esposa, asegurando que las mujeres pasaran largas horas en el hogar, dando cuenta de una posición social que lo permitía (Parker, 1996, pp. 63- 64).

Por su parte, Georgina Gluzman señala que en la Buenos Aires posrevolucionaria la educación y el estatuto de las mujeres suscitó grandes debates, incluso en periódicos de redacción femenina. La discusión en torno al aprendizaje de las labores de la aguja aparece reflejada como una doble capacidad de realzar moralmente y de proteger en caso de necesidad (Gluzman, 2017, pp. 139, 143 y 145).

Uno de los bordados que trascendieron en la historia y hoy son parte de nuestra colección son los que realizó Isabel Dorrego para su padre. En una nota escrita por Manuel Dorrego, el 13 de diciembre de 1828, antes de ser fusilado, esboza una lista de sus deudas y deudores, así como también un reparto de objetos que lega, donde menciona: "A mi querida Isabel, te devuelvo los tiradores que hiciste à tu infortunado padre" ${ }^{28}$ Es interesante destacar que estos tiradores fueron donados el 21 de octubre de 1890, convirtiéndose en los primeros objetos textiles que hacen referencia a una mujer. Su donante Margarita Rosenthal de Canaveri, nieta de Manuel Dorrego, le expresa a Adolfo Carranza lo siguiente:

\footnotetext{
Poseedora de algunos objetos que pueden enriquecer el "Museo Histórico" bajo su dirección, he creido que sin sacrificar la estimación y veneración filial que ellos me merecen, por los recuerdos que evocan, debia entregarlos á la custodia de quien sabrá apreciarlos debidamente, y darles el destino que les corresponde, como que pertenecieron ó se refieren á un personage que ha pasado á figurar entre las páginas de nuestra historia.

Ellos son: un par de suspensores y un anillo de que se despojó mi inolvidable abuelo el Coronel Dorrego, para enviarlos á sus hijas Isabel y Ángela, mi tia la primera, y mi idolatrada madre la segunda, á quien Dios tenga en santa paz, cuando victima aquel, de uno de los errores de que se resiente nuestro génesis histórico, se sentaba en el banquillo, para ser ejecutado, despues de fortificado su espiritu con los auxilios de la religión católica, único consuelo según sus mismas palabras en tan critico y supremo instante. ${ }^{29}$
}

\footnotetext{
${ }^{28}$ Carta del Coronel Manuel Dorrego dirigida a su esposa e hijas, copia litográfica por Bacle y cia., 1828. Museo Histórico Nacional, Buenos Aires. Número de inventario: 14477.

${ }^{29}$ Carta de Margarita Rosenthal de Canaveri a Adolfo Carranza, Buenos Aires, 21 de octubre de 1890. AH MHN, FAPC/FGF, Libro de Donación N 1, folio 44.
} 
Figura 31. Tiradores de Manuel Dorrego

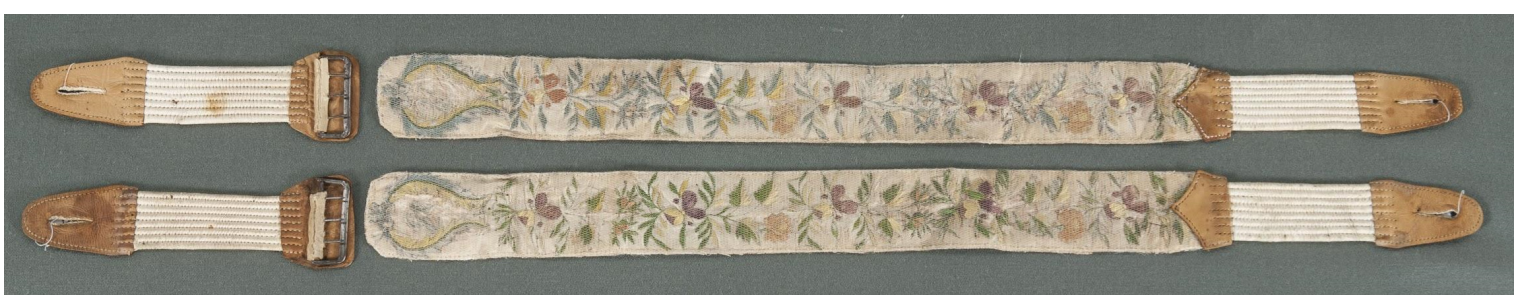

Fuente: Museo Histórico Nacional, Buenos Aires. Número de inventario: 2494.

A partir de la inspección ocular, notamos que la bordadora recurrió a motivos florales y agregó, como era costumbre en este tipo de piezas, unas iniciales que hoy en día no llegan a identificarse con claridad. La seda de los tiradores y sus bordados se encuentran hoy deteriorados, posiblemente atribuido a la constante exposición a la que fueron sometidos durante la historia del museo. En relevamientos fotográficos anteriores podemos advertir que las iniciales bordadas mencionadas son A y B, una en cada tirador, las cuales corresponden a Ángela Baudrix, esposa de Dorrego, siendo un posible homenaje de su hija hacia su madre. Isabel, la hija a la que Manuel Dorrego se refiere como artífice de los tiradores, tenía 12 años al momento del hecho.

Los bordados, tanto en prendas de vestir como en la decoración del hogar, eran signos de estatus. El uso de bordados mostraba que quien los usaba contaba con el dinero suficiente para costear prendas con tal trabajo profesional o que tenía el privilegio de contar con mujeres en su familia con tiempo para trabajar ellas mismas en sus bordados (Larkin, 2017, p. 74). Siguiendo el análisis de Alison Larkin acerca de la diferenciación entre bordados profesionales y domésticos, la autora señala que, hacia principios del siglo XIX, la vestimenta femenina no contaba con bordados importantes, que quedaban relegados a los accesorios. En el caso de los hombres de civil, los bordados primaban en los chalecos y en accesorios, como los tiradores. Con respecto a la factura de los bordados, la autora señala algunos aspectos que pueden permitir a quienes trabajamos con piezas históricas diferenciar entre bordados realizados de manera profesional y aquellos realizados en el ámbito doméstico; en ambos casos, las mujeres recibían instrucción desde pequeñas, ya sea para realizar estas tareas como medio de vida (tanto en tareas domésticas remuneradas, como en talleres textiles) o como signo de prestigio en las familias que pudiesen permitir esa actividad. 
Cabe señalar que algunos autores mencionan que tanto Ángela como Isabel, dado el estado económico ruinoso en el que sucumben tras el fusilamiento de Dorrego, debieron trabajar como costureras en una ropería que proveía uniformes al Ejército hasta que recuperaron su pensión (Méndez, 2003, p. 37; Di Meglio, 2014, p. 373).

Por otro lado, resulta oportuno reparar en piezas relacionadas con mujeres y contiendas bélicas, en las que podemos ver ejemplos claros del registro del "uso público de un saber hacer típicamente femenino y asociado a la esfera doméstica como el bordado" (Gluzman, 2017, p. 156). Una fue ingresada como "bandera bordada por las damas argentinas residentes en Montevideo para el ejército del Gral. Lavalle", otra como "fragmento central de un estandarte obsequiado al general Quiroga por las damas mendocinas" y otra como "escudo de la bandera obsequiada por las damas argentinas al Alte. Guillermo Brown”. El uso genérico del término "damas", a la hora de registrar estas piezas, hace que se desdibuje el trabajo de las mujeres que realizaron y obsequiaron este trabajo, sumado a que el dato de la procedencia geográfica tiende a englobar a un colectivo y nuevamente evita la personalización.

Un caso en el que, a partir de este trabajo, encontramos la referencia sobre su bordadora es el del estandarte que usó el ejército del Coronel José María Paz en la batalla de Caaguazú, en el que curiosamente Matilde Olazábal utilizó no solo los hilos metálicos para bordar el sol de la pieza, sino que también, a modo de firma, registró su nombre en la misma superficie textil.

\section{Figuras 32 y 33. Estandarte de la batalla de Caaguazú y detalle con la firma de Matilde Olazábal}

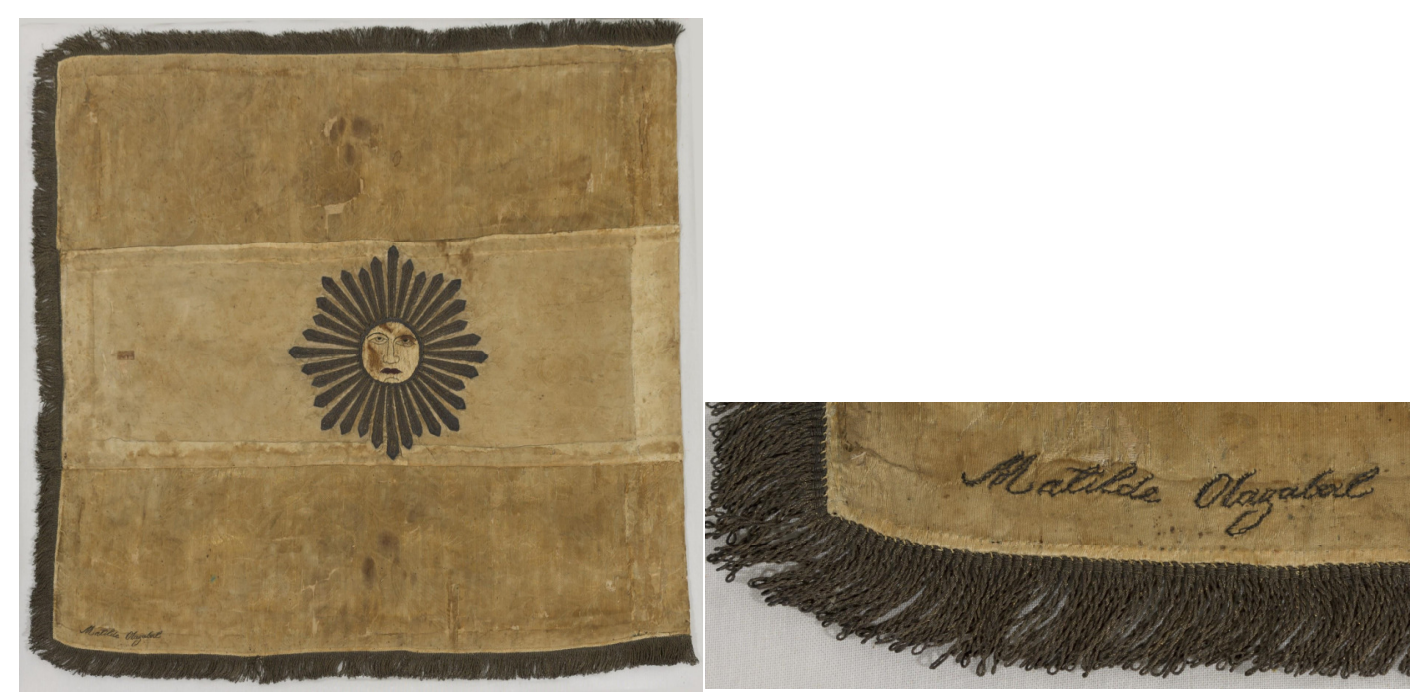

Fuente: Museo Histórico Nacional, Buenos Aires. Número de inventario: 2517. 
Por último, no queríamos dejar de hacer mención al poncho obsequiado por el cacique Mariano Rosas a Lucio V. Mansilla y que habría sido tejido por su esposa; según se evidencia en la carta enviada por el mismo propietario y donante a Adolfo Carranza el 5 de octubre de 1909: “Ahí va la encomienda, el poncho pampa tejido por la mujer de Mariano Rozas. El ribete de la boca y de lo demás no es, como verá, obra pampa. Se lo puse para evitar que se desflecara". ${ }^{30}$ Una vez más, nos encontramos frente a la imposibilidad de contar con la información completa sobre quién fue la mujer que tejió esta pieza, dado que, hasta el momento, no fue posible hallarlo en los registros del museo y en la bibliografía consultada.

\section{Conclusiones}

Una vez realizado este primer acercamiento a la colección textil femenina del museo, podemos concluir lo siguiente: los textiles analizados pueden ser datados aproximadamente desde el año 1800 al 1865 y, en su mayoría, fueron usados o realizados por mujeres de la elite. Las piezas analizadas nos hablan de trabajos que se traducen en costuras y bordados manuales sobre géneros que, en su mayoría, son de seda o algodón. Los accesorios también evidencian un trabajo artesanal y el empleo de costosos materiales.

A partir del estudio del textil y su documentación, pudimos reconstruir también la biografía de muchas de estas mujeres que no solo fueron esposas de militares o políticos (dato que desde sus inicios el museo consignó como suficientes), sino que también desarrollaron acciones dignas de ser mencionadas, como los trabajos textiles, su aporte en tiempo, trabajo y dinero en las guerras, su participación en organismos públicos como la Sociedad de Beneficencia, su condición migrante en tiempos de guerra o los sucesivos partos a los que se sometían sus cuerpos, entre otros aspectos que pudimos agregar a sus biografías.

Las donaciones o adquisiciones de las piezas analizadas, se realizaron entre el año 1890 y 1950, con un predominio del criterio de incorporar los objetos de mujeres que hubieran sido hijas, madres, esposas o hubieran formado parte del entorno de algún hombre destacado de la historia.

\footnotetext{
${ }^{30}$ Carta de donación de Lucio V. Mansilla a Adolfo Carranza, 5 de octubre de 1909. AH MHN, FAPC/FGF, Libro de Donación $N^{\circ} 10$, folio 43.

Inferimos que se trata del mismo poncho al cual hace referencia en su libro Una excursión a los indios ranqueles de la siguiente manera, en un diálogo entre el cacique Mariano Rosas, hijo adoptivo de Juan Manuel de Rosas, y él mismo:

“Iba a salir del toldo; me llamó y sacándose el poncho pampa que tenía puesto, me dijo, dándomelo.

-Tome, hermano, úselo en mi nombre, es hecho por mi mujer principal.

(...) La gran significación que el poncho de Mariano Rosas tenía, no era que pudiera servirme de escudo en un peligro, sino que el poncho tejido por la mujer principal, es entre los indios un gaje de amor, es como el anillo nupcial entre los cristianos". (Mansilla, 1984, p. 332). (La negrita es nuestra).
} 
Todos los textiles mencionados fueron exhibidos en algún momento en el museo, hecho que explica su frágil estado de conservación en general, con deterioros ocasionados por largos períodos de exposición a la radiación y manipulaciones incorrectas.

El estudio de la colección de indumentaria femenina nos permitió, junto con la consulta de otras fuentes documentales e iconográficas, pensar y rearmar el cuerpo y la presencia de las mujeres de una forma más cercana a la realidad, abriendo una serie de interrogantes sobre su papel en la historia y su forma de representarlas dentro del museo. Por otro lado, al relacionarnos con su forma de vestir, nos permitió dar un primer paso para conocer más sobre la vida cotidiana de nuestros antepasados, cuestión central que atrae a los visitantes del MHN y a quienes trabajamos a diario con las colecciones del museo, al incorporar un carácter civil a una colección que, por lo general, se encuentra fuertemente asociada a lo militar.

La consideración de las piezas textiles como fuentes, vinculándolas con la documentación relacionada y la historiografía sobre la indumentaria, la producción, circulación y comercialización de textiles en el Buenos Aires del siglo XIX, nos ha permitido conocer sobre su materialidad, su confección y manufactura, así como también saber sobre las formas de uso de las mismas y aspectos de la vida cotidiana.

\section{Referencias bibliográficas}

Appadurai, A. (Ed.) (1991). La vida social de las cosas. Perspectiva cultural de las mercancías. México: Editorial Grijalbo.

Asociación Amigos de los Museos Histórico Nacional y del Cabildo (1969). Catálogo Exposición del traje en el Río de la Plata, desde el siglo XVII hasta el siglo XX. Buenos Aires.

Barrancos, D. (2007). Mujeres en la sociedad argentina: una historia de cinco siglos. Buenos Aires: Editorial Sudamericana.

Bermejo, T. y Cortés Aliaga, G. (2019). Museos híbridos, feministas y descolonizados. Caiana, 14, 56-62. Disponible en http://caiana.caia.org.ar/resources/uploads/14pdf/Caiana14D_intro.pdf (Descargado 24/06/2020).

Carman, C. M. (2013). Los orígenes del Museo Histórico Nacional. Buenos Aires: Prometeo Libros.

Cortés Aliaga, G. y Cuevas Pérez, J. (2018). Género y Discipulaje. Los casos de Clara Filleul y Procesa Sarmiento en el "Taller Monvoisin". Análisis de las colecciones del Museo Nacional de Bellas Artes y del Museo Histórico Nacional. Santiago: Fondo de apoyo a la Investigación Nacional. Disponible en https://www.investigacion.patrimoniocultural.gob.cl/694/articles-92432_archivo_01.pdf (Descargado 24/06/2020).

Criado Boado, F. (2012). Arqueológicas: La razón perdida. La construcción de la inteligencia arqueológica. Barcelona: Ed. Bellaterra.

Di Lorenzo, S, Villaronga, M, y Wortley, A, (2007). Conservación y puesta en valor del patrimonio textil del Museo Histórico Nacional de Buenos Aires, Argentina. Actas XXI Comité Nacional de Conservación Textil, 21-26. Disponible en: http://www.cnct.cl/?page id=214 (Descargado 20/11/2020). 
106 | Vestidas en la historia: una mirada a la colección de indumentaria femenina...

Di Meglio, G. (2014). Manuel Dorrego: vida y muerte de un líder popular. Buenos Aires: Edhasa.

Gluzman, G, (2017). Adornar la nación. Artes femeninas en la Argentina entre la Revolución de Mayo y el rosismo (1810-1852). ARENAL, 24 (1), 135-167. Disponible en https://revistaseug.ugr.es/index.php/arenal/article/view/3089 (Descargado 23/06/2020).

Gutiérrez Usillos, A. (2012). Ausencias y silencios. Patrimonio en femenino. Disponible en https://sede.educacion.gob.es/publiventa/descarga.action?f_codigo_agc=14138C (Descargado 24/06/2020).

Katz, M. (2017). Los artesanos proteccionistas. Buenos Aires, primera mitad del siglo XIX. Economía y Política, 4 (2), 5-36. Disponible en http://www.economiaypolitica.cl/index.php/eyp/article/view/44 (Descargado 21/06/2019).

Larkin, A. (2017). Professional and Domestic Embroidery on Men's Clothing in the Later Eighteenth Century. The Journal of Dress History, 1 (1), 74-83.

Leonardi, R. y Vaisman, S. (2017). Los devenires de la Indumentaria porteña, Buenos Aires 18001852. Buenos Aires: Diseño Editorial.

López Fernández Cao, M. (2011). ¿Es necesario un museo de mujeres? Disponible en https:/sede.educacion.gob.es/publiventa/patrimonio-en-femenino/cultura-sociedadarte/14187C (Descargado 24/06/2020).

Mansilla, L. V. (1984). Una excursión a los indios ranqueles. Buenos Aires. Biblioteca Ayacucho. Disponible en: http://www.iphi.org.br/sites/filosofia_brasil/Lucio_mansilla__Una_excursion_a_los_indios_ranqueles.pdf (Descargado 20/11/2020).

Méndez, A. (2003). La generación y su tiempo. Buenos Aires: Editorial Dunken.

Mitidieri, G. (2017). Costureras, modistas, sastres y aprendices. Una aproximación al circuito de trabajo de la costura. Buenos Aires, 1852-1862 (Tesis de Licenciatura en Historia). Universidad de Buenos Aires, Buenos Aires.

Moreyra, C. (2018). Cuerpos vestidos. Indumentaria femenina en Córdoba (Argentina) siglo XIX. ARENAL, 25 (2), 501-527. Disponible en https://www.researchgate.net/publication/329835588_Cuerpos_vestidos_Indumentaria_femenina_en_Cordoba_Argentina_siglo_XIX (Descargado 13/11/2019).

Parker, R. (1996). The Subversive Stitch: Embroidery and the Making of the Feminine. London: Tauris and Co Ltd.

Publicaciones del Museo Histórico Nacional (1939). El Museo Histórico en su Cincuentenario 1889-1939. Buenos Aires: Peuser.

Root, R. A. (2014). Vestir la nación. Buenos Aires: Edhasa.

Para citar este artículo:

Ullua, Juliana y Van Peteghem, Inés (2020). Vestidas en la historia: una mirada a la colección de Indumentaria femenina del Museo Histórico Nacional (Buenos Aires, Argentina). Anuario de la Escuela de Historia Virtual, 18, 69-106. 